\title{
Automated Mapping of Convective Clouds (AMCC) Thermodynamical, Microphysical, and CCN Properties from SNPP/VIIRS Satellite Data
}

\author{
Zhiguo Yue, ${ }^{\mathrm{a}, \mathrm{b}}$ DANiEl Rosenfeld, ${ }^{\mathrm{c}}$ GUIHUA LiU, ${ }^{\mathrm{a}}$ Jin DAI, ${ }^{\mathrm{a}}$ Xing Yu, ${ }^{\mathrm{a}}$ YANNIAN Zhu, ${ }^{\mathrm{a}}$ \\ EyAl HASHIMSHONI, ${ }^{\mathrm{c}}$ XIAOHONG XU, ${ }^{\mathrm{a}}$ YING HUI, $^{\mathrm{a}}$ AND Oliver LAUER ${ }^{\mathrm{d}}$ \\ ${ }^{a}$ Meteorological Institute of Shaanxi Province, Xi'an, China \\ ${ }^{\mathrm{b}}$ Office of Weather Modification of Shaanxi Province, Xi'an, China \\ ${ }^{\mathrm{c}}$ Institute of Earth Sciences, Hebrew University of Jerusalem, Jerusalem, Israel \\ ${ }^{\mathrm{d}}$ Multiphase Chemistry Department, Max Planck Institute for Chemistry, Mainz, Germany
}

(Manuscript received 7 June 2018, in final form 19 January 2019)

\begin{abstract}
The advent of the Visible Infrared Imager Radiometer Suite (VIIRS) on board the Suomi NPP (SNPP) satellite made it possible to retrieve a new class of convective cloud properties and the aerosols that they ingest. An automated mapping system of retrieval of some properties of convective cloud fields over large areas at the scale of satellite coverage was developed and is presented here. The system is named Automated Mapping of Convective Clouds (AMCC). The input is level-1 VIIRS data and meteorological gridded data. AMCC identifies the cloudy pixels of convective elements; retrieves for each pixel its temperature $T$ and cloud drop effective radius $r_{e}$; calculates cloud-base temperature $T_{b}$ based on the warmest cloudy pixels; calculates cloud-base height $H_{b}$ and pressure $P_{b}$ based on $T_{b}$ and meteorological data; calculates cloud-base updraft $W_{b}$ based on $H_{b}$; calculates cloud-base adiabatic cloud drop concentrations $N_{d, a}$ based on the $T-r_{e}$ relationship, $T_{b}$, and $P_{b}$; calculates cloud-base maximum vapor supersaturation $S$ based on $N_{d, a}$ and $W_{b}$; and defines $N_{d, a} / 1.3$ as the cloud condensation nuclei $(\mathrm{CCN})$ concentration $N_{\mathrm{CCN}}$ at that $S$. The results are gridded $36 \mathrm{~km} \times 36 \mathrm{~km}$ data points at nadir, which are sufficiently large to capture the properties of a field of convective clouds and also sufficiently small to capture aerosol and dynamic perturbations at this scale, such as urban and land-use features. The results of AMCC are instrumental in observing spatial covariability in clouds and CCN properties and for obtaining insights from such observations for natural and man-made causes. AMCC-generated maps are also useful for applications from numerical weather forecasting to climate models.
\end{abstract}

\section{Introduction}

Satellite retrievals are the only practical way of observing clouds and aerosol properties on regional and global scales. Recently Rosenfeld et al. (2016) was able to use such satellite retrievals to provide estimation of cloud condensation nuclei $(\mathrm{CCN})$ concentration $N_{\mathrm{CCN}}$ from satellite measurements. In this study we take the next step and present a method for application of the $\mathrm{CCN}$ retrievals for mapping large areas. The main part of this paper presents the method of $\mathrm{CCN}$ mapping. The introduction prepares the background by reviewing the physical basis for $\mathrm{CCN}$ retrieval.

Aerosols affect clouds mainly by their $\mathrm{CCN}$ activity, which influences cloud drop number concentrations and

Corresponding author: Daniel Rosenfeld, daniel.rosenfeld@ mail.huji.ac.il albedo, which in turn is followed by a cascade of adjustment processes that can either buffer or amplify the primary effect on cloud radiative properties (Stevens and Feingold 2009). Therefore, much of the science of atmospheric chemistry and aerosols has been devoted to ways by which aerosol size and composition determine their $\mathrm{CCN}$ and ice nucleating particle activity (Andreae and Rosenfeld 2008). Satellite observation retrievals are the only practical way to quantify the effective radiative forcing by aerosol cloud interactions at a global scale. Aerosol optical-depth retrieval near clouds is plagued by artifacts (Várnai and Marshak 2009) and ambiguity (Quaas et al. 2010), and it is only crudely related to CCN (Andreae 2009). Even if AOD could be retrieved accurately, it would likely be poorly correlated with the actual CCN that affects clouds (Stier 2016). Furthermore, aerosol effects on cloud composition are entangled with meteorological conditions, mainly as manifested by updraft 
TABLE 1. The products of the AMCC.

\begin{tabular}{|c|c|c|c|}
\hline Name & Parameter and unit & Source of calculation & Error \\
\hline Lat & Center lat of $96 \times 96$ pixels moving window $\left({ }^{\circ}\right)$ & VIIRS L1b image data & $0.0001^{\circ}$ \\
\hline Lon & Center lon of $96 \times 96$ pixels moving window $\left({ }^{\circ}\right)$ & VIIRS L1b image data & $0.0001^{\circ}$ \\
\hline $\bar{H}$ & Avg alt of the $96 \times 96$ pixels moving window $(\mathrm{m})$ & VIIRS L1b image data & $1 \mathrm{~m}$ \\
\hline$T_{\text {prf }}$ & Temperature profile $\left({ }^{\circ} \mathrm{C}\right)$ & NCEP FNL data & \\
\hline$H_{\mathrm{prf}}$ & Height profile $(\mathrm{m})$ & NCEP FNL data & \\
\hline $\mathrm{RH}_{\text {prf }}$ & Relative humidity profile (\%) & NCEP FNL data & \\
\hline$P_{\mathrm{LCL}}$ & Pressure of LCL (hPa) & NCEP FNL data & \\
\hline$T_{\mathrm{LCL}}$ & Temperature of LCL $\left({ }^{\circ} \mathrm{C}\right)$ & NCEP FNL data & \\
\hline$H_{\mathrm{LCL}}$ & Height of LCL (m) & NCEP FNL data & \\
\hline $\mathrm{RH}_{\mathrm{LCL}}$ & Relative humidity of LCL (\%) & NCEP FNL data & \\
\hline$r_{e, b}$ & Cloud-base drop effective radius $(\mu \mathrm{m})$ & Satellite retrieval & $8 \%$ \\
\hline$T_{14}$ & Temperature of precipitation initiation & Satellite retrieval & $0.2^{\circ} \mathrm{C}$ \\
\hline$D_{14}$ & Depth of precipitation initiation & $T_{14}+\mathrm{NCEP} F N L$ & $150 \mathrm{~m}$ \\
\hline$T_{b}$ & Cloud-base temperature $\left({ }^{\circ} \mathrm{C}\right)$ & Satellite retrieval & $1.1^{\circ} \mathrm{C}$ \\
\hline$P_{b}$ & Cloud-base pressure (hPa) & $T_{b}+$ NCEP FNL & $15 \mathrm{hPa}$ \\
\hline$H_{b}$ & Cloud-base height above surface $(\mathrm{m})$ & $T_{b}+$ NCEP FNL & $150 \mathrm{~m}$ \\
\hline$W_{b}$ & Cloud-base updraft $\left(\mathrm{m} \mathrm{s}^{-1}\right)$ & $H_{b}$ [Eq. (5)] & $27 \%$ \\
\hline$S$ & Cloud-base max supersaturation (\%) & $T_{b}, P_{b}, W_{b}$, and $N_{d, a}[$ Eq. (1)] & $25 \%$ of $S$ in percent \\
\hline$N_{\mathrm{CCN}}$ & $\mathrm{CCN}$ concentration of cloud base $\left(\mathrm{mg}^{-1}\right)$ & $N_{\mathrm{CCN}}=N_{d, a} / 1.3[$ Eq. (2)] & $30 \%$ \\
\hline$T_{\text {top }}$ & Temperature of cloud top $\left({ }^{\circ} \mathrm{C}\right)$ & Satellite retrieval & $0.2^{\circ} \mathrm{C}$ \\
\hline$H_{\text {top }}$ & Height of cloud top (m) & $T_{t o p}+\mathrm{NCEP}$ FNL data & $150 \mathrm{~m}$ \\
\hline$P_{\text {top }}$ & Pressure of cloud top (hPa) & $T_{\text {top }}+\mathrm{NCEP}$ FNL data & $15 \mathrm{hPa}$ \\
\hline$T_{\text {con }}$ & Condensational-growing initial temperature & Satellite retrieval & $1.1^{\circ} \mathrm{C}$ \\
\hline$T_{\text {coa }}$ & Coalescence initial temperature & Satellite retrieval & $1.1^{\circ} \mathrm{C}$ \\
\hline$T_{r}$ & Rainout initial temperature & Satellite retrieval & $1.1^{\circ} \mathrm{C}$ \\
\hline$T_{\text {mix }}$ & Mixed-phase initial temperature & Satellite retrieval & $1.1^{\circ} \mathrm{C}$ \\
\hline$T_{g}$ & Cloud glaciation temperature $\left({ }^{\circ} \mathrm{C}\right)$ & Satellite retrieval & $1.1^{\circ} \mathrm{C}$ \\
\hline
\end{tabular}

speeds. Without simultaneously retrieving both cloud active aerosols and cloud-base updrafts $W_{b}$, it is impossible to disentangle and extract the net aerosol effects. To make matters worse, the ability to retrieve $W_{b}$ via satellite has been nonexistent until our very recent studies (Zheng and Rosenfeld 2015; Zheng et al. 2015, 2016).

Cloud pixel temperature-cloud drop effective radius, or $T-r_{e}$, relationships were first constructed by Rosenfeld and Lensky (1998) for inferring the microstructure and precipitation forming processes of convective clouds. The $T-r_{e}$ relationships are used to retrieve glaciation temperature $T_{g}$ of convective clouds (Rosenfeld et al. 2011; Yuan et al. 2010) and the depth of precipitation initiation. This depth $D_{14}$ is the height within the cloud at which the retrieved $r_{e}$ reaches $14 \mu \mathrm{m}$-the point above which the probability of precipitation increases (Freud et al. 2008; Freud and Rosenfeld 2012; Rosenfeld 1999; Rosenfeld and Gutman 1994; Zhu et al. 2015). The observed brightness temperature at the top of this layer is $T_{14}$. The depth of precipitation initiation $D_{14}$ may also be related to convective storm severity (Rosenfeld et al. 2008a). As a result of the previously mentioned studies, it is now possible to use VIIRS for retrieving a set of convective cloud products that include $T_{b}, H_{b}, W_{b}, S, N_{d, a}, N_{\mathrm{CCN}}, T_{14}, D_{14}, T_{\text {top }}$, $H_{\text {top }}, T_{\text {con }}, T_{r}, T_{\text {mix }}$, and $T_{g}$ (see the definitions of all parameters in Table 1).

Although retrieved cloud microphysical properties have been realized by using the Visible Infrared Imaging Radiometer Suite (VIIRS) 375-m data of the Suomi National Polar-Orbiting Partnership (SNPP) spacecraft (Rosenfeld et al. 2014a,b, 2016), the selection of the analyzed convective cloud clusters in an area of interest was done manually by an interactive software package. But the process is tedious and time-consuming, and it is impractical to retrieve large-scale data of VIIRS. The motivation of this paper is to introduce an automated system that may lead to operational retrieval and mapping of the properties of these convective clouds at regional to global scales. This retrieval system will be helpful to understand the impacts of aerosols on convective clouds on regional or global scales, and for further investigating the impacts of anthropogenic aerosol on climate and weather.

The outline of this paper is as follows: Section 2 reviews the method of retrieving $\mathrm{CCN}$, section 3 describes the methods of the Automated Mapping of Convective Clouds (AMCC), section 4 presents some examples of the AMCC retrieval from VIIRS data, section 5 


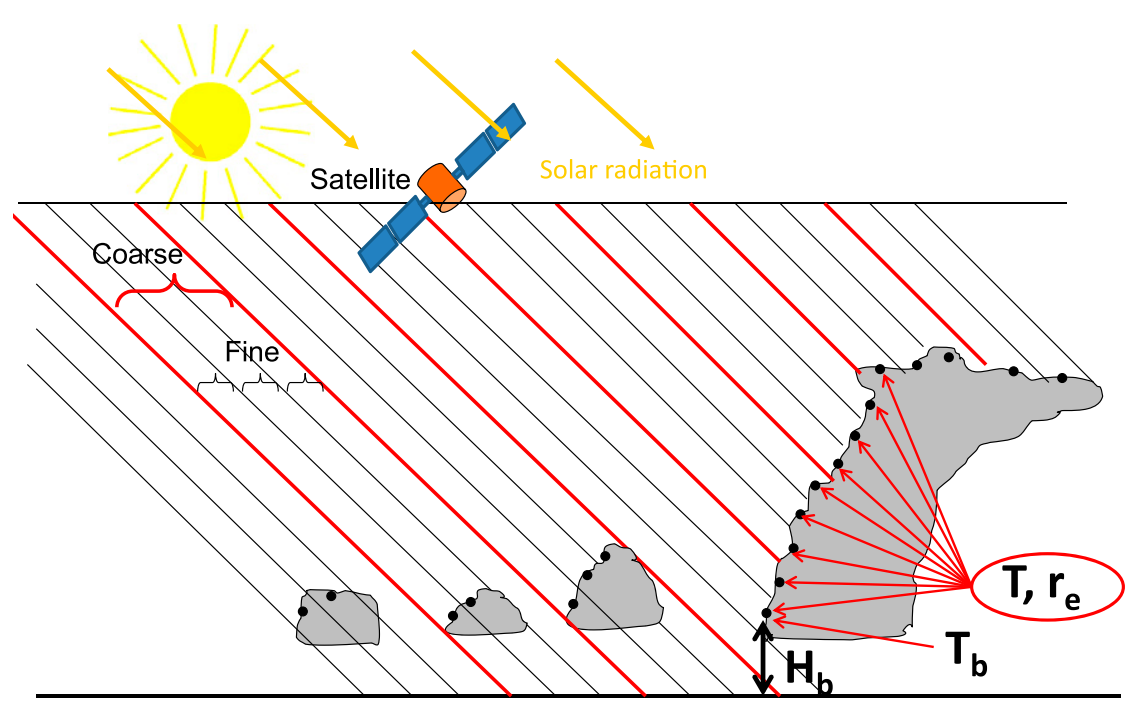

FIG. 1. Advantages of high-resolution satellite retrievals from a field of convective clouds (from Fig. 8 of Rosenfeld 2018). The schematic shows that SNPP/VIIRS 375-m data (thin black lines) have the ability to resolve the vertical structure of the small boundary layer clouds that MODIS 1-km data (red lines) cannot resolve.

discusses the limitations of applicability, and section 6 summarizes and concludes the paper.

\section{A review of the method of retrieving $\mathrm{CCN}$ from satellite}

The full description of the method is provided by Rosenfeld et al. (2016) and references therein. Here a brief review is provided, because this paper builds on that method and takes it to the next level of automated mapping of $\mathrm{CCN}$ and related cloud properties.

The approach relies on the fact that, at cloud base, adiabatic drop concentrations $N_{d, a}$, updraft $W_{b}$, and peak vapor supersaturation $S$ are related to each other by

$$
S=C W_{b}^{3 / 4} N_{d, a}^{-1 / 2},
$$

where the coefficient $C$ is calculated from cloud-base temperature $T_{b}$ and pressure $P_{b}$ (Pinsky et al. 2012). The $T_{b}$ and $P_{b}$ are based on satellite retrievals. The approach is to retrieve $N_{d, a}$ and $W_{b}$ and then to obtain $S$ from Eq. (1). Then, $N_{d, a}$ is the CCN concentration at supersaturation $S$.

The $N_{d, a}$ is retrieved from the shape of the $T-r_{e}$ relationships, as observed by satellite. Figure 1 illustrates the retrieval of $r_{e}(T)$ for a cluster of convective clouds. A cluster of convective clouds has cloudy pixels with tops ranging from just above cloud base to the tallest cloud in the scene, thus providing many cloudy pixels with pairs of $T$ and $r_{e}$, which represent the cloud vertical profile in the scene. The microphysical evolution of the top of a single cloud as it grows is similar to the composite of a snapshot cloud ensemble with tops at different heights (Lensky and Rosenfeld 2006). The median value of $r_{e}$ for each $1^{\circ} \mathrm{C}$ interval of $T$ constitutes $r_{e}(T)$. The warmest cloudy $T$ in the cluster constitutes $T_{b}$.

The method to calculate $N_{d, a}$ of convective clouds is put forward (Freud et al. 2011). It relies on the observation that $r_{e}$ in convective clouds is approximately adiabatic while the liquid water content (LWC) may diverge from adiabatic because of mixing and evaporation (Beals et al. 2015; Burnet and Brenguier 2007; Freud et al. 2011; Paluch 1979). Therefore, the adiabatic LWC is the adiabatic drop number concentrations multiplying the average mass of an adiabatic cloud droplet. It is used to retrieve $N_{d, a}$ as follows (Rosenfeld et al. 2014a):

$$
\begin{aligned}
N_{d, a} & =\mathrm{LWC}_{a} / \mathrm{Mr}_{v, a}, \\
\operatorname{Mr}_{v, a} & =(4 / 3) \rho \pi r_{v}^{3}, \quad \text { and } \\
r_{v}^{3} & =k r_{e}^{3},
\end{aligned}
$$

where $\mathrm{LWC}_{a}$ is the cloud adiabatic liquid water content calculated by an adiabatic elevated parcel from cloud base to isotherm $T, \mathrm{Mr}_{v, a}$ is the mass of an adiabatic cloud drop, $\rho$ is the water density, and $r_{v}$ is mean volume radius. The $k$ is the droplet size distribution dispersion, which is coupled to cloud vertical profile development and should change depending on cloud base, cloud-top height, and cloud type in addition to entrainment of dry air with the cloud (Brenguier et al. 2011; Miller et al. 2016). Since extensive aircraft 
observations in India, Israel, and Texas show that the ratio between $r_{e}$ and $r_{v}$ of the convective clouds is $1.08 \pm 0.01(k=0.79 \pm 0.02)$ with little variance, $r_{e}=$ $1.08 r_{v}$ is used (Freud et al. 2011). This is limited to conditions of boundary layer convective clouds without significant coalescence or secondary drop activation above cloud base, which are required for the method of CCN retrieval (Rosenfeld et al. 2016). The calculated $N_{d, a}$ is used in Eq. (1) for calculating $S$.

Equation (1) also requires $W_{b}$ as input. This is calculated as a simple linear function of cloud-base height above the surface $H_{b}$, according to Eq. (5), a linear empirical relationship (Zheng and Rosenfeld 2015):

$$
W_{b}=0.0009 H_{b},
$$

where $H_{b}$ is the distance from surface to cloud base in meters and the unit of $W_{b}$ is meters per second.

The accuracy of these calculations relies on the accuracy of $T_{b}, W_{b}$, and satellite-retrieved $r_{e}$ (Rosenfeld et al. 2016). The possibility of obtaining useful accuracy began with the advent of the $S N P P$, which was launched on 28 October 2011. The VIIRS of SNPP contains 5 channels of $375-\mathrm{m}$ imagery resolution and 17 channels of $750-\mathrm{m}$ moderate resolution at nadir. The spatial resolution of $375 \mathrm{~m}$ represents a reduction of the pixel area by a factor of 7 at nadir (the factor becomes even higher away from nadir) relative to the $1-\mathrm{km}$ pixels of MODIS in the thermal IR bands (Rosenfeld et al. 2014b). It brings the most evident improvement in viewing the top of small-scale features in the thermal channels (Hillger et al. 2013), such as small convective clouds. Rosenfeld et al. (2014b) developed a method to apply VIIRS Imager 375-m data for retrieving highresolution $T-r_{e}$ relations (Fig. 1). Its advantages in retrieving the microphysical properties and precipitation forming process of convective clouds under different aerosol conditions were demonstrated (Rosenfeld et al. 2014b; Zhu et al. 2015). However, the standard cloud products of the VIIRS Environmental Data Records are derived at the base resolution of $750 \mathrm{~m}$ (Kopp et al. 2014). To resolve the scale of small convective elements, we used the cloud products that were developed based on the 375-m resolution data, which consist of cloud-base height $H_{b}$ (Zhu et al. 2014) and the $T-r_{e}$ profiles (Rosenfeld et al. 2014b).

Retrieving $r_{e}$ at a resolution of $375 \mathrm{~m}$ is more susceptible to 3D effects than at 1000 or $750 \mathrm{~m}$. The 3D effects, such as illuminating and shadowing, can lead to significant uncertainty in $r_{e}$ (Davis and Marshak 2010; Marshak and Davis 2005; Marshak et al. 2006; Zhang et al.2012). It is also found that $3 \mathrm{D}$ effects tend to have stronger impact on retrieval $r_{e}$ of $2.1 \mu \mathrm{m}$ than $3.7 \mu \mathrm{m}$, where the absorption is largest and mean free path of the photons is shortest (Zhang et al. 2012). Therefore our retrievals are based on $3.7 \mu \mathrm{m}$, and we limited the geometry only to near backscattering angles with deviations of up to $\sim \pm 35^{\circ}$, which is approximated by satellite zenith angles between $-20^{\circ}$ and $50^{\circ}$, where illuminating and shadowing is minimal. The shadowing effect increases (Fig. 1) and leads to an overestimate of $r_{e}$ when the satellite is observed westward. Therefore the backscatter angle is an important factor to limit the retrieval. The early afternoon time of the SNPP overpass means that backscatter angles occur between the ranges of satellite zenith angles of $-20^{\circ}$ and $50^{\circ}$, where a positive angle is to the east of the orbit track.

Figure 1 illustrates how the $375-\mathrm{m}$ resolution of the VIIRS Imager is advantageous, especially for the smaller convective clouds, and thus provides more accurate retrievals at the initial stage of cloud formation and near the bases of more developed clouds (Rosenfeld et al. 2014b). This allows for the retrieval of $T_{b}$ (Zhu et al. 2014) with improved accuracy, which validated by a combination of ceilometer and sounding showed a root-mean-square (RMS) error of $1.1^{\circ} \mathrm{C}$ for the satellite retrieved $T_{b}$. In building on this result, the calculation of $H_{b}$ and the vapor mixing ratio of the boundary layer are within an accuracy of approximately $10 \%$. A method is developed to retrieve $W_{b}$ based on the satellite retrieved $T_{b}, H_{b}$, and surface temperature (Zheng et al. 2015). The RMS error was $0.41 \mathrm{~m} \mathrm{~s}^{-1}$, as validated by lidar-measured updraft speed at the Southern Great Plains (SGP) Atmospheric Radiation Measurement Program site.

The VIIRS $375-\mathrm{m}$ satellite-retrieved $T-r_{e}$ profiles and $T_{b}$ are applied to retrieve $\mathrm{CCN}$ by the validation of the satellite retrieved $\mathrm{CCN}$ against ground-based observations at three sites in Oklahoma and the Amazon River Basin and on board a ship as shown in Fig. 2, with an accuracy of about $\pm 30 \%$ (Rosenfeld et al. 2014a, 2016).

\section{Method of the AMCC}

The key point in the automated retrieval system is the compilation of our various methods that work as separate programs into one complete automated package. The AMCC is composed of 10 modules including data processing, image segmentation, identification of cloud pixel, $r_{e}$ retrieval, convective clouds detection, $T_{b}$ retrieval, identification of the adiabatic $r_{e}, \mathrm{CCN}$ retrieval, quality control, and graphical display. The flowchart of AMCC is presented in Fig. 3. Its final output is gridded datasets of microphysical properties for convective clouds at regional or global scales. 


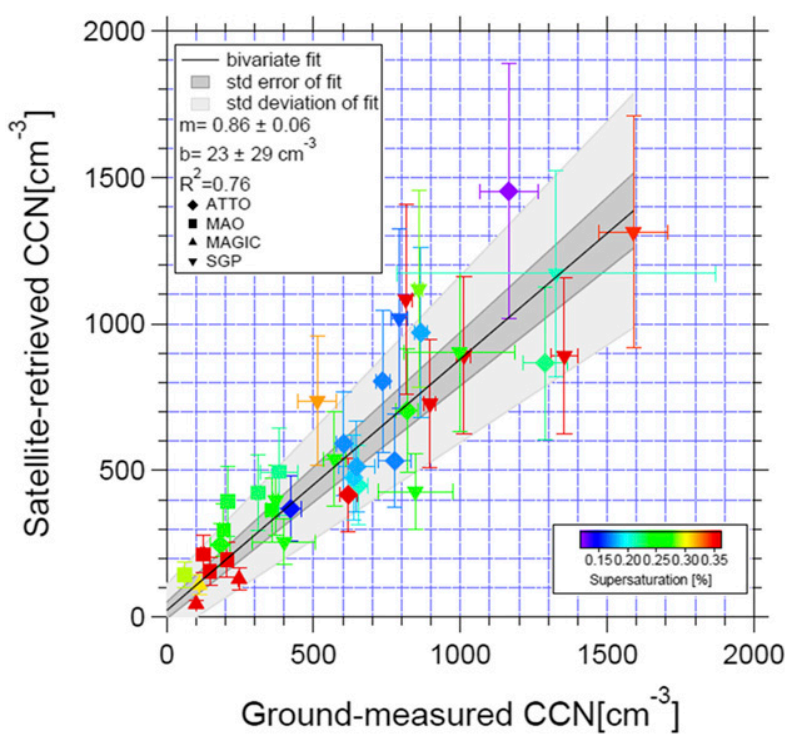

FIG. 2. Comparison of CCN concentration between the satelliteretrieved measurements and the ground-based instrument measurements (from Fig. 3 of Rosenfeld et al. 2016).

\section{a. Data processing}

\section{1) VIIRS DATA}

The input data are the VIIRS sensor data record (SDR) published via the NOAA Comprehensive Large ArrayData Stewardship System (CLASS) (https://www.bou. class.noaa.gov/saa/products/search?sub_id=0\&datatype_ family=VIIRS_SDR). It contains 5 channels of $375-\mathrm{m}$ high-resolution data, 17 channels of 750-m mediumresolution data, and terrain-corrected geolocation data. The high-resolution data have 6400 and 6144 pixels at the cross-track and along-track directions, respectively. A "bow tie" geometric correction is conducted after the raw data are read. Each pixel is calibrated based on the supplied calibration coefficient, and its reflectance, brightness temperature, and geometry are assigned. The quantities of each pixel at medium-resolution $(750 \mathrm{~m})$ wave bands are replicated to a pixel resolution at the high resolution $(375 \mathrm{~m})$. In this manner, each of the four pixels that are replicated shares the same value as the original medium-resolution pixel.

\section{2) NCEP FNL DATA}

To reconstruct the vertical distribution of meteorological elements at the time of the satellite overpass, the NCEP final operational global analysis (FNL) data (http://rda.ucar.edu/datasets/ds083.2/) were chosen as the main supporting data. The weather meteorological data $1^{\circ} \times 1^{\circ}$ latitude and longitude grid for satellite overpass time were obtained by the linear interpolation between two FNL data at a 6-h interval. Then, the interpolated-in-time FNL data closest to the center of the moving window is used for this moving window with $96 \times 96$ VIIRS Imager pixels of $375 \mathrm{~m}$.

\section{b. VIIRS image segmentation}

The retrieval is applied to one field of convective clouds at a time within a moving window in the segment. The window size that was found to be optimal is $96 \times 96$ VIIRS Imager pixels of $375 \mathrm{~m}$, which form a rectangle of $36 \mathrm{~km} \times 36 \mathrm{~km}$ region at nadir. This size is near optimal because it is sufficiently large for including usually a sufficient number of convective cells at various stages of growing to provide a stable $T-r_{e}$ relationship. On the other hand, this size is sufficiently small for resolving the effects of local aerosol and land surface perturbations on the $T-r_{e}$ and the subsequently retrieved cloud properties and $\mathrm{CCN}(\mathrm{S})$. This size is the default; it may be changed, if desired.

The default moving or jumping interval is set as the same as the size of the moving window, 96 pixels along the two directions in each segment. A full granule contains 66 and 64 windows along the across-track and track directions, respectively. Every available CPU gets quantities of all pixels in one of the segmented windows and conducts the retrieval based on the methods described in sections $3 \mathrm{c}-3 \mathrm{~g}$.

\section{c. Cloud masking}

The objective of this study is retrieving and mapping the properties of convective clouds at regional scales. The retrieved cloud properties are based on cloudy pixels. Therefore, the logic is, first, identifying cloudy pixels; second, identifying the subset of convective pixels. Sections $3 c(1)$ and $3 c(2)$ describe the rejection of snow/ice pixels and surface contamination pixels, section $3 \mathrm{c}(3)$ shows how to reject thin cirrus, section $3 c(4)$ describes how to identify optically thick cloud pixels with a lookup table, and section $3 c(5)$ shows how to reject overlapped thin upper clouds by brightness temperature difference (Fig. 4; Table 2).

\section{1) REJECTION OF SNOW/ICE PIXELS}

Since snow/ice surface and cloud pixels have similar characteristics in the visible channel, snow/ice pixels must be identified. The pixels of snow/ice are rejected by the snow/ice surface detection method proposed by Godin (2014) and Hutchison et al. (2013), which is similar to currently VIIRS operational algorithms. The pixels that meet the following five conditions simultaneously are identified as snow/ice: 


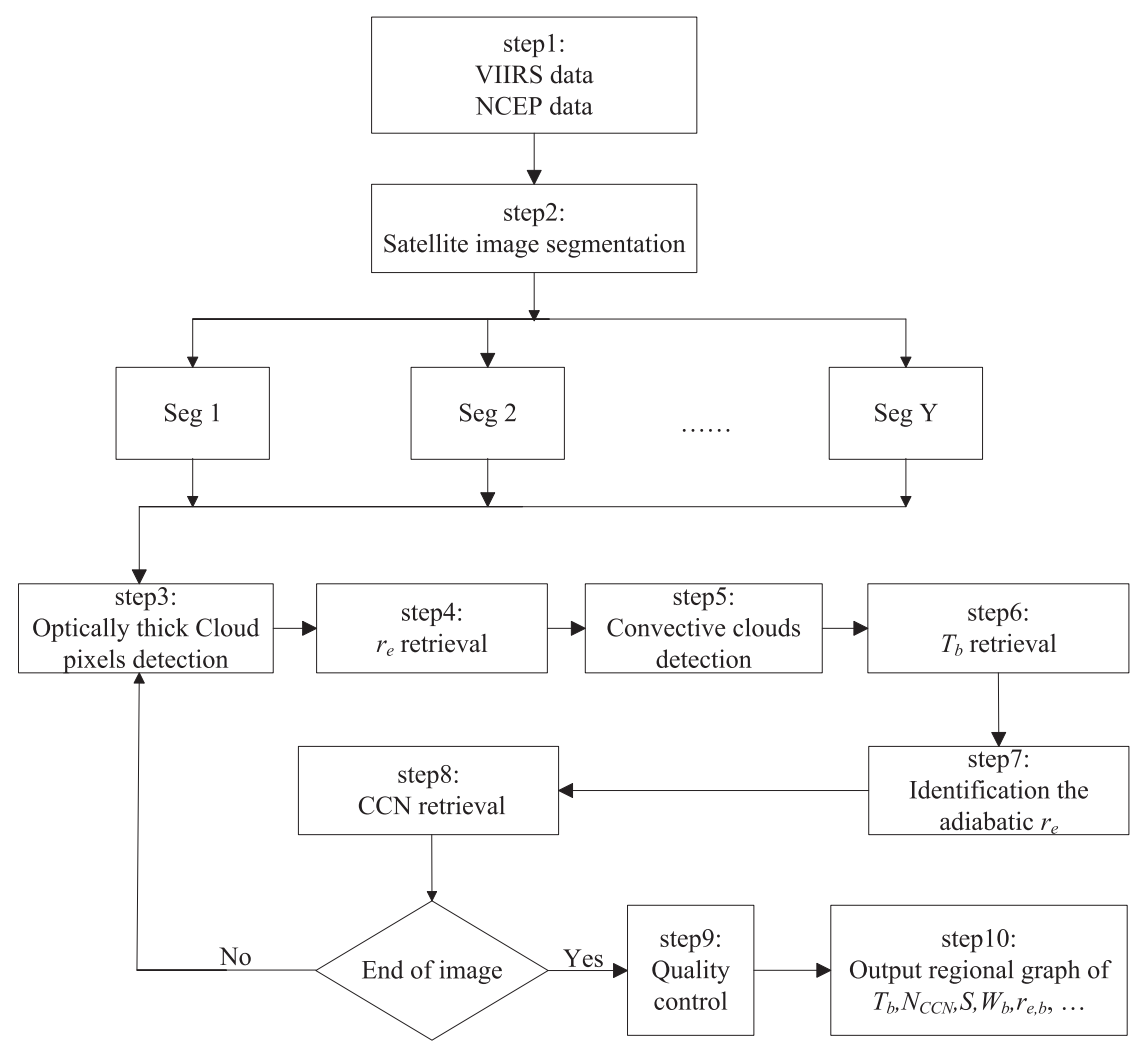

FIG. 3. Flowchart of the AMCC system.

1) The normalized difference snow index [NDSI $=$ $\left.\left(\rho_{0.56 \mathrm{~m}}-\rho_{1.6 \mathrm{~m}}\right) /\left(\rho_{0.56 \mathrm{~m}}+\rho_{1.6 \mathrm{~m}}\right)\right]$ exceeds 0.4 ,

2) $T_{3.7 \mathrm{~m}}-T_{4.0 \mathrm{~m}}<15^{\circ} \mathrm{C}$,

3) $\rho_{0.8 \mathrm{~m}}>21 \%$,

4) $T_{11 \mathrm{~m}}<2^{\circ} \mathrm{C}$, and

5) $T_{2 \mathrm{~m} \_ \text {sfc }}-T_{11 \mathrm{~m}}<25^{\circ} \mathrm{C}$.

\section{2) REJECTION OF SURFACE CONTAMINATION PIXELS}

For a better cloud mask, a threshold of normalized differential vegetation index (NDVI) is calculated by the reflectance at the 0.64 - and $0.865-\mu \mathrm{m}$ channels of $375-\mathrm{m}$ resolution. Here we mask out a pixel if it is "greenish" and too warm, for example, NDVI $>0.15$ (default value in this study) and the $11.45-\mu \mathrm{m}$ brightness temperature $T_{11 \mathrm{~h}}$ greater than the $2-\mathrm{m}$ temperature above the surface $T_{2 \mathrm{~m} \_ \text {sfc }}$ from the FNL data.

\section{3) REJECTION OF THIN CIRRUS PIXELS}

Cirrus distorts the retrieved cloud microphysical properties. The $1.38-\mu \mathrm{m}$ channel of $750-\mathrm{m}$ resolution $\rho_{1.38 \mathrm{~m}}$ is particularly sensitive to highly elevated cirrus clouds, because the reflected radiation from the ground is absorbed strongly by water vapor above the low-level cloud tops (Meyer et al. 2004; Roskovensky and Liou 2003). The cirrus parameter $P_{\text {ci }}$ developed by Roskovensky and Liou (2003) is used for cirrus screening. It can be expressed as

$$
P_{\mathrm{ci}}=\exp \left[\mathrm{RR} \times A+\left(\mathrm{BTD}_{8.6-11 \mathrm{~m}}-B\right)\right],
$$

where $\mathrm{RR}$ is the ratio between $\rho_{1.38 \mathrm{~m}}$ and $\rho_{0.6 \mathrm{~h}}, A$ is its scaling factor, $\mathrm{BTD}_{8.6-11 \mathrm{~m}}$ represents the moderateresolution $8.6-11-\mu \mathrm{m}$ brightness temperature difference, and $B$ is the $\mathrm{BTD}_{8.6-11 \mathrm{~m}}$ offset. Here, $A=2 /\left(M_{\mathrm{RR} \text { clr }}+\right.$ $\left.\sigma_{\mathrm{RRclr}}\right), B=M_{\mathrm{RRclr}}+\sigma_{\mathrm{RRclr}}+2$, where $M$ and $\sigma$ represent the mean and standard deviation of RR and $\mathrm{BTD}_{8.6-11 \mathrm{~m}}$ pixels for the clear sky $\left[\rho_{0.6 \mathrm{~h}}<\rho_{\text {cld_min }} ; \rho_{\text {cld_min }}\right.$ is the minimum reflectivity that can be considered to be cloud, as described in section 3c(4)] in a moving window. Pixels with $P_{\text {ci }}$ greater than 1 are identified as thin cirrus.

\section{4) IDENTIFICATION OF OPTICALLY THICK CLOUDS}

The satellite retrieved effective radius can be overestimated in thin and broken clouds because of surface contamination (Coakley et al. 2005). This issue disappears only when clouds are optically thick, for example, nonbroken clouds with optical thickness greater than $\sim 8$ in the visible spectrum (Rosenfeld et al. 2004). Therefore, we need to identify the cloudy pixels that are deep enough to retrieve reliable effective radius and are also 


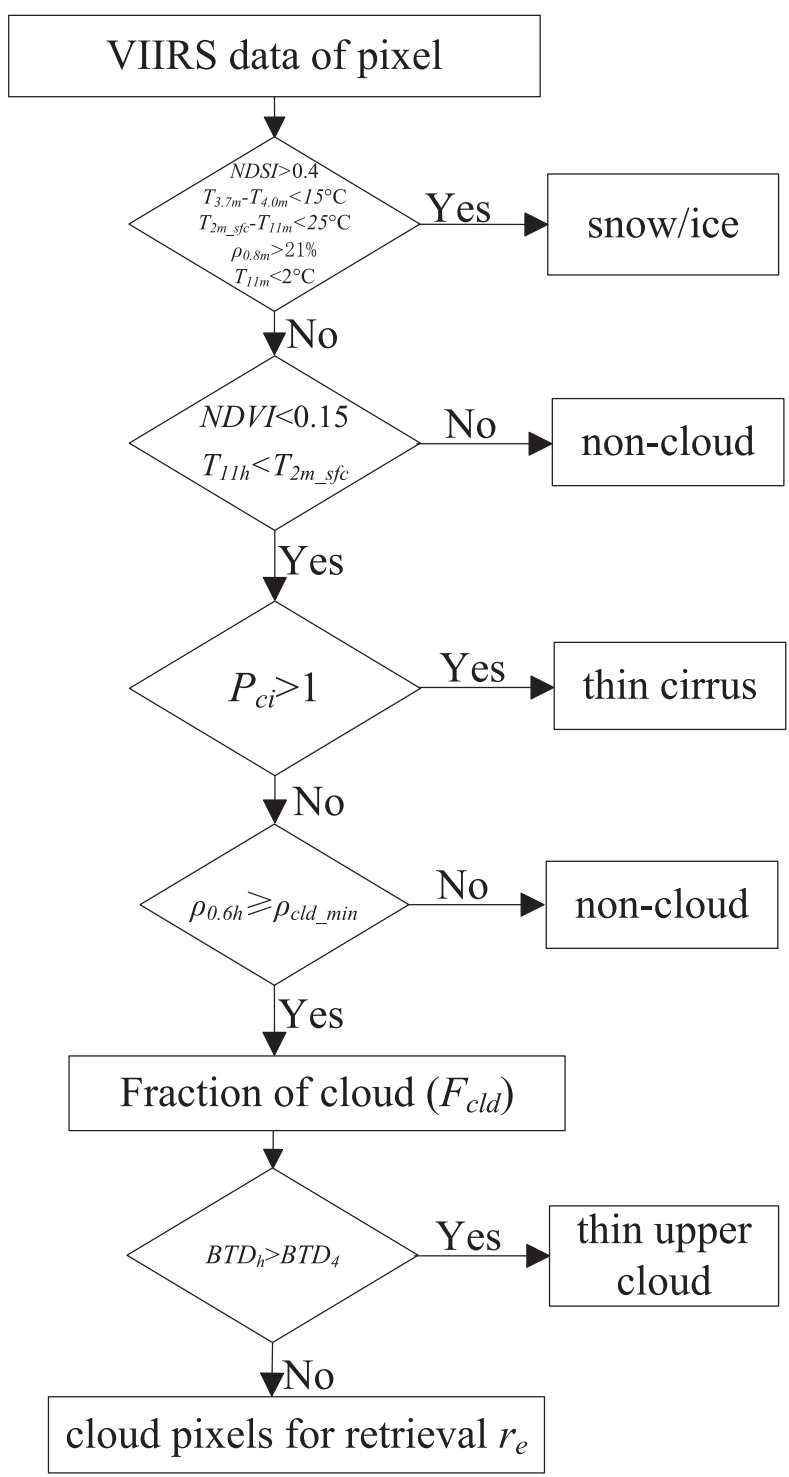

FIG. 4. Flowchart of automatic identification of cloudy pixels; the descriptions of the symbols in the flowchart are listed in Table 2.

minimally affected by surface contamination due to partial pixel filling. The cloud visible reflectance is determined not only by cloud optical thickness alone but also by the geometries of satellite and sun and by the surface reflectance. Therefore, we created a lookup table (LUT) of minimum reflectance of cloud for $0.64-\mu \mathrm{m}$ reflectance $\left(\rho_{\text {cld_min }}\right)$ channel (LUT cld_min_0.6 $\mu \mathrm{m}_{\text {) }}$ with optical thickness equal to 10 , for given surface reflectance, satellite and sun geometries, and surface reflectance by the Santa Barbara DISORT Atmospheric Radiative Transfer (SBDART) radiative transform model. For sea surface, we applied the SBDART surface type "sea water," and for land surface we calculated $0.64-\mu \mathrm{m}$ reflectance from 0 to 0.6 by interval of 0.05 . Besides surface properties, the rest of the inputs are solar zenith angle SolZ $\left(0^{\circ}-85^{\circ} ; 5^{\circ}\right.$ interval $)$, satellite zenith angle SatZ $\left(0^{\circ}-70^{\circ} ; 5^{\circ}\right.$ interval $)$, and the solarsatellite relative azimuth angle relA $\left(0^{\circ}-180^{\circ} ; 10^{\circ}\right.$ interval). For each $96 \times 96$ pixel window, the surface property is identified as land or sea or a mixture of land and sea (land surface reflectance is obtained for cloudfree pixels):

1) For clouds over sea surface, we can get the $\rho_{\text {cld_min }}$ based on the sun and satellite geometries alone, because surface type does not change.

2) For clouds over land surface, it is more complicated since we need to obtain the surface reflectance before we can use the LUT $_{\text {cld_min_o.6 } \mu \mathrm{m}}$. We set the initial reflectance threshold of the high-resolution visible channel $\rho_{0.6 \mathrm{~h}}$ to a value of 0.4 (Baum and Trepte 1999; Rosenfeld and Lensky 1998; Rosenfeld et al. 2014b). These pixels over land surface with $\rho_{0.6 \mathrm{~h}}<0.4$ are identified as initial surface pixels of noncloud (PIX sfc_init $\left._{\text {in }}\right)$. In a partly cloudy scene, the warmest brightness temperature in the PIX sfc_init $_{\text {in most likely }}$ to be the surface. After sorting the PIX $\mathrm{X}_{\text {sfc_init }}$ pixels in descending order with respect to $T_{11 \mathrm{~h}}$, the surface temperature $T_{\text {sfc_1max }}$ is assigned as the temperature of the first peak in pixel frequency, when counted in $1^{\circ} \mathrm{C}$ bins. If the ratio of PIX sfc $\_$init $_{\text {to }}$ total number of land pixels within the window $\left(\mathrm{RATIO}_{\text {sfc }}\right)$ is greater than 0.1 , the average $\rho_{0.6 \mathrm{~h}}$ of PIX sfc_init $_{\text {inat }}$ thave temperatures higher than $T_{\text {sfc_1max }}$ is taken as the initial surface reflectance $\rho_{\text {sfc_init }}$, and the $\rho_{\text {cld_min }}$ is obtained as the initial cloud reflectance threshold $\rho_{\text {cld_init }}$ by finding the closest values corresponding to the SolZ, SatZ, relA of moving window center, and $\rho_{\text {sfc_init }}$ in the LUT $_{\text {cld_min_0.6 }} \mu \mathrm{m}$. The PIX ${ }_{\text {sfc }}$ pixels with $\rho_{0.6 \mathrm{~h}}<$ $\rho_{\text {cld_init }}$ are identified as assumed to be cloud free, and the surface reflectance $\rho_{\text {sfc }}$ of these pixels is obtained in a manner similar to that of $\rho_{\text {sf__init. }}$. Again, using the $\rho_{\text {sfc }}$ and sun and satellite geometries in the $\mathrm{LUT}_{\text {cld_min_} \_.6 \mu \mathrm{m}}$, the $\rho_{\text {cld_min }}$ over land could be obtained. If the RATIO ${ }_{\text {sfc }}$ is less than 0.1, it is concluded that there is no reliable surface reflectance, and the above calculating process is repeated using $\rho_{\text {sfc_init }}=0.15$.

3) For the mixture of land and sea, we separate the whole window into subwindows of land and sea and get the $\rho_{\text {cld_min }}$ individually.

Based on the listed procedures, we can identify cloudy pixels dynamically according the sun and satellite geometries and surface reflectance. The ratio of cloud pixels passed through this test to the total number of 
TABLE 2. The symbols used in this paper, with their descriptions and units.

\begin{tabular}{|c|c|c|c|}
\hline Symbol & Parameter and unit & Source of calculation & Error \\
\hline$r_{e}$ & Cloud drop effective radius $(\mu \mathrm{m})$ & Satellite retrieval & $8 \%$ \\
\hline$W_{b}$ & Cloud-base updraft $\left(\mathrm{m} \mathrm{s}^{-1}\right)$ & $H_{b}[$ Eq. (5)] & $27 \%$ \\
\hline$T$ & Cloud pixel temperature $\left({ }^{\circ} \mathrm{C}\right)$ & Satellite retrieval & $0.2^{\circ} \mathrm{C}$ \\
\hline$T_{14}$ & Temperature of precipitation initiation $\left({ }^{\circ} \mathrm{C}\right)$ & Satellite retrieval & $0.2^{\circ} \mathrm{C}$ \\
\hline$D_{14}$ & Depth of precipitation initiation & $T_{14}+$ NCEP FNL & $150 \mathrm{~m}$ \\
\hline$T_{g}$ & Cloud glaciation temperature $\left({ }^{\circ} \mathrm{C}\right)$ & Satellite retrieval & \\
\hline$T_{b}$ & Cloud-base temperature $\left({ }^{\circ} \mathrm{C}\right)$ & Satellite retrieval & $1.1^{\circ} \mathrm{C}$ \\
\hline$P_{b}$ & Cloud-base pressure $(\mathrm{hPa})$ & $T_{b}+$ NCEP FNL & $15 \mathrm{hPa}$ \\
\hline$H_{b}$ & Cloud-base height above surface $(\mathrm{m})$ & $T_{b}+$ NCEP FNL & $150 \mathrm{~m}$ \\
\hline$S$ & Cloud-base max supersaturation (\%) & $T_{b}, P_{b}, W_{b}$, and $N_{d, a}[$ Eq. (1)] & $25 \%$ of $S$ in percent \\
\hline$N_{d, a}$ & Adiabatic cloud drop concentrations $\left(\mathrm{mg}^{-1}\right)$ & Eq. (2) & $30 \%$ \\
\hline $\mathrm{Mr}_{v, a}$ & Adiabatic cloud drop mass (mg) & Eq. (3) & \\
\hline$N_{\mathrm{CCN}}$ & $\mathrm{CCN}$ concentration at cloud base $\left(\mathrm{mg}^{-1}\right)$ & $N_{\mathrm{CCN}}=N_{d, a} / 1.3$ & $30 \%$ \\
\hline$\rho_{0.56 \mathrm{~m}}$ & $0.555-\mu \mathrm{m}$ visible reflectance of $750-\mathrm{m}$ resolution & VIIRS L1b image data & $2 \%$ \\
\hline$\rho_{0.6 \mathrm{~h}}$ & $0.64-\mu \mathrm{m}$ visible reflectance of $375-\mathrm{m}$ resolution & VIIRS L1b image data & $2 \%$ \\
\hline$\rho_{0.8 \mathrm{~h}}$ & $0.865-\mu \mathrm{m}$ visible reflectance of $375-\mathrm{m}$ resolution & VIIRS L1b image data & $2 \%$ \\
\hline$\rho_{0.8 \mathrm{~m}}$ & $0.865-\mu \mathrm{m}$ visible reflectance of $750-\mathrm{m}$ resolution & VIIRS L1b image data & $2 \%$ \\
\hline$\rho_{1.38 \mathrm{~m}}$ & $1.378-\mu \mathrm{m}$ visible reflectance of $750-\mathrm{m}$ resolution & VIIRS L1b image data & $2 \%$ \\
\hline$\rho_{1.6 \mathrm{~h}}$ & $1.61-\mu \mathrm{m}$ visible reflectance of $375-\mathrm{m}$ resolution & VIIRS L1b image data & $2 \%$ \\
\hline$\rho_{1.6 \mathrm{~m}}$ & $1.61-\mu \mathrm{m}$ visible reflectance of $750-\mathrm{m}$ resolution & VIIRS L1b image data & $2 \%$ \\
\hline$\rho_{3.7 \mathrm{~h}}$ & $3.74-\mu \mathrm{m}$ visible reflectance of $375-\mathrm{m}$ resolution & Satellite retrieval & \\
\hline$\rho_{\text {cld_min }}$ & 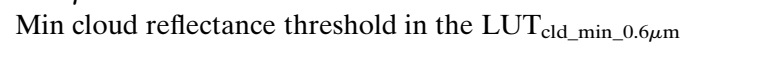 & $\begin{array}{l}\text { A radiative transform model } \\
\text { (SBDART) }\end{array}$ & \\
\hline$P_{\mathrm{ci}}$ & Cirrus parameter of moving window & Eq. (6) & \\
\hline PIX $_{\text {sfc_init }}$ & The pixels over land surface with $\rho_{0.6 \mathrm{~h}}<0.4$ & & \\
\hline NDVI & Normalized differential vegetation index & $\mathrm{NDVI}=\left(\rho_{0.8 \mathrm{~h}}-\rho_{0.6 \mathrm{~h}}\right) /\left(\rho_{0.8 \mathrm{~h}}+\rho_{0.6 \mathrm{~h}}\right)$ & \\
\hline NDSI & Normalized difference snow index & $\mathrm{NDSI}=\left(\rho_{0.56 \mathrm{~m}}-\rho_{1.6 \mathrm{~m}}\right) /\left(\rho_{0.56 \mathrm{~m}}+\rho_{1.6 \mathrm{~m}}\right)$ & \\
\hline$T_{3.7 m}$ & $3.7-\mu \mathrm{m}$ brightness temperature of $750-\mathrm{m}$ resolution $\left({ }^{\circ} \mathrm{C}\right)$ & VIIRS L1b image data & $0.4 \%$ \\
\hline$T_{4.0 \mathrm{~m}}$ & $4.05-\mu \mathrm{m}$ brightness temperature of $750-\mathrm{m}$ resolution $\left({ }^{\circ} \mathrm{C}\right)$ & VIIRS L1b image data & $0.4 \%$ \\
\hline$T_{8.6 \mathrm{~m}}$ & $8.55-\mu \mathrm{m}$ brightness temperature of $750-\mathrm{m}$ resolution $\left({ }^{\circ} \mathrm{C}\right)$ & VIIRS L1b image data & $0.4 \%$ \\
\hline$T_{11 \mathrm{~m}}$ & $10.76-\mu \mathrm{m}$ brightness temperature of $750-\mathrm{m}$ resolution $\left({ }^{\circ} \mathrm{C}\right)$ & VIIRS L1b image data & $0.4 \%$ \\
\hline$T_{11 \mathrm{~h}}$ & $11.45-\mu \mathrm{m}$ brightness temperature of $375-\mathrm{m}$ resolution $\left({ }^{\circ} \mathrm{C}\right)$ & VIIRS L1b image data & $0.4 \%$ \\
\hline$T_{12 \mathrm{~m}}$ & $12.0-\mu \mathrm{m}$ brightness temperature of $750-\mathrm{m}$ resolution $\left({ }^{\circ} \mathrm{C}\right)$ & VIIRS L1b image data & $0.4 \%$ \\
\hline$T_{2 \mathrm{~m} \_\mathrm{sfc}}$ & 2-m temperature above the surface $\left({ }^{\circ} \mathrm{C}\right)$ & NCEP FNL & \\
\hline$\Delta T_{11 \mathrm{~h}}$ & Pixel homogeneity & Eq. (7) & \\
\hline $\mathrm{BTD}_{h}$ & $\begin{array}{l}\text { Difference of brightness temperature of cloudy pixels for high } \\
\text { resolution }(375 \mathrm{~m})\end{array}$ & $\begin{array}{l}\text { Recalibrated } T_{11 \mathrm{~h}}-T_{11 \mathrm{~m}}(\text { Rosenfeld } \\
\quad \text { et al. 2014b) }\end{array}$ & \\
\hline $\mathrm{BTD}_{4}$ & The $\mathrm{BTD}_{h}$ of 25th-percentile pixels no. of moving window & VIIRS L1b image data & \\
\hline CVI & Convection index of moving window & & \\
\hline$F_{\text {cld }}$ & Fraction of cloud pixels of moving window & & \\
\hline$F_{\text {re }}$ & The fraction of $r_{e}>0$ pixels of moving window & & \\
\hline $\bar{r}_{e}$ & Mean $r_{e}$ of moving window $(\mu \mathrm{m})$ & & \\
\hline
\end{tabular}

pixels of the moving window is defined as the fraction of cloud $F_{\text {cld }}$.

\section{5) REJECTION OF MULTILAYER CLOUD PIXELS}

Because brightness temperature of the colder cloud pixels is affected by less water vapor absorption, the difference of brightness temperature (BTD) of a thick cloud should decrease with decreasing temperature. However, when a thin cloud overlaps another clouds, the brightness temperature and reflectance of these cloud pixels are disturbed, and the BTD will be increased (Inoue 1987). It is necessary to exclude those cloud pixels that are optically thin or newly formed water clouds over lower clouds because they lead to an overestimate the BTD. Traditionally, BTD between 11 and $12 \mu \mathrm{m}$ was used to reject such types of clouds (Inoue 1985). Rosenfeld et al. (2014b) have developed a method to obtain BTD of $375-\mathrm{m}$ resolution $\left(\mathrm{BTD}_{h}\right)$ because of the fact that $12.0 \mu \mathrm{m}$ is not available separately at $375-\mathrm{m}$ resolution of VIIRS. For a given $T_{11 \mathrm{~h}}$, pixels that have passed through cloud mask of sections $3 c(2)$ and $3 c(3)$ (PIX cld ) in this moving window are sorted from small to large $\mathrm{BTD}_{h}$, and the $\mathrm{BTD}_{h}$ of 25 thpercentile pixel number is marked as $\mathrm{BTD}_{4}$ for this $T_{11 \mathrm{~h}}$. 
The $\mathrm{BTD}_{4}$ values from the highest to the lowest $T_{11 \mathrm{~h}}$ of PIX $_{\text {cld }}$ are calculated. If $\mathrm{BTD}_{4}$ of a given $T_{11 \mathrm{~h}}$ increases with decreasing $T_{11 \mathrm{~h}}$, it is replaced by the monotonically decreasing or invariant $\mathrm{BTD}_{4}$, which is obtained by the linear interpolation of the nearest $\mathrm{BTD}_{4}$ with decreasing $T_{11 \mathrm{~h}}$. Then, the monotonic reduction is enforced for $\mathrm{BTD}_{4}$ of PIX cld $_{\text {with decreasing }} T_{11 \mathrm{~h}}$ because only optically thin upper clouds can increase $\mathrm{BTD}_{4}$ with decreasing $T_{11 \mathrm{~h}}$. $\mathrm{BTD}_{4}$ dynamically obtained for each $T_{11 \mathrm{~h}}$ of PIX $\mathrm{Pld}_{\text {cld }}$ in each moving window is used as a criterion for identifying overlapped thin upper clouds. If $\mathrm{BTD}_{h}$ of a cloud pixel is greater than $\mathrm{BTD}_{4}$ corresponding to its $T_{11 \mathrm{~h}}$, it will be masked as overlapped thin upper clouds and rejected.

\section{d. $r_{e}$ retrieval}

The 3.74- $\mu \mathrm{m}$ reflectance $\rho_{3.7 \mathrm{~h}}$ is used to retrieve $r_{e}$ from a

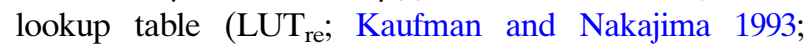
Rosenfeld and Lensky 1998) for the pixels identified as cloudy using the cloud screening described above. The $\mathrm{LUT}_{\mathrm{re}}$ is established for an effective radius of the water cloud drop for given $r_{e}, \rho_{3.7 \mathrm{~h}}$, SolZ, SatZ, and relA (Rosenfeld and Lensky 1998; Rosenfeld et al. 2014b). The $\rho_{3.7 \mathrm{~h}}$ of larger cloud particles decreases to near the channel noise level, so the maximum size of $r_{e}$ retrieved by this method is $40 \mu \mathrm{m}$. Note that, because the liquid phase $r_{e}$ is from 1 to $40 \mu \mathrm{m}$ in $\mathrm{LUT}_{\text {re }}$, the allowable retrieval solution space for liquid clouds is limited to $1-40 \mu \mathrm{m}$. The percentage of $r_{e}>0$ pixels in the moving window $F_{\mathrm{re}}$ is obtained.

\section{e. Convective clouds detection}

The clouds addressed in this study are generated by convection that is propelled by surface heating and consist of convective clouds with flat base at the lifting condensation level (LCL), as illustrated in Fig. 1. Therefore, early-afternoon satellite overpasses are best suited for observing such convective clouds over land. Boundary layer convective clouds over ocean are much less affected by the diurnal cycle.

Aircraft measurements of vertical microphysical profiles of such convective clouds show that cloud droplet $r_{e}$ increases monotonically from cloud base to top in developing convective clouds (Andreae et al. 2004; Konwar et al. 2012; Prabha et al. 2011; Rosenfeld and Lensky 1998; Rosenfeld and Woodley 2000; Rosenfeld et al. 2006; Braga et al. 2017), and cloud-top $r_{e}$ in different stages of a vertically growing convective clouds cluster are similar to the $r_{e}$ of different heights within a single convective cloud. This relationship of increasing $r_{e}$ with height is often ambiguous for nonconvective clouds, however. As the temperature decreases with the increase of height, the positive correlation between $r_{e}$ and cloudtop height is characterized by a corresponding negative correlation between $r_{e}$ and temperature. Thus, the $T-r_{e}$ relationships can be used to separate a mixture of layer and convective clouds (Lensky and Rosenfeld 1997) and applied to detection of convective clouds. The following four steps are used to distinguish the convective and nonconvective clouds in each moving window.

1) The analysis is done on a small running window of $25 \times$ $25=625$ pixels in a moving window, centered at the tested cloudy pixel. The $r_{e}$ and $T$ values of an inner small running window are sorted from high to low by temperature. The correlation coefficient between the sorted $T$ and $r_{e}$ is calculated as the relation of convection $R_{\mathrm{cv}}$. A negative $R_{\mathrm{cv}}$ means increasing $r_{e}$ with decreasing $T$, which characterizes a convective cloud.

2) The $R_{\mathrm{cv}}$ of each cloud pixel in the moving window is calculated.

3) The average value of $R_{\mathrm{cv}}$ of all cloud pixels in the moving window is defined as the convection index $(\mathrm{CVI})$. If CVI $>0$, the cloud in this moving window is not a convective cloud.

4) The $T-r_{e}$ profile of retrieval $\mathrm{CCN}$ is required to start from cloud base. If most pixels of the moving window are cloudy, there is a risk of insufficient documentation of the lower parts of the clouds. On the other extreme, the $T-r_{e}$ profile cannot be established with too few cloud pixels with $r_{e}$. Aircraft measurements show that the cloud base $r_{e}$ is generally in the range of $1-8 \mu \mathrm{m}$ and that formation of precipitation-sized drops occurs when $r_{e}>13 \mu \mathrm{m}$ (Braga et al. 2017; Rosenfeld et al. 2006, 2008b). Too large of a mean $r_{e}$, or $\bar{r}_{e}$, indicates glaciated clouds. Therefore, a cloud is identified as water convective cloud when CVI $<0$ and $F_{\mathrm{cld}}<95 \%$ and $F_{\mathrm{re}}>0.4 \%$ and $\bar{r}_{e}<35 \mu \mathrm{m}$.

\section{f. The retrieval of convective clouds base temperature $\left(T_{b}\right)$}

The cloud base is taken as the warmest cloudy pixel in a moving window of convective clouds having different extent of vertical development above their base. Cloud base is assumed to be at constant heights for convective clouds over a well-mixed boundary layer. Under these conditions, the warmest cloudy pixel can approximate $T_{b}$. Here the algorithm of Zhu et al. (2014) is used for retrieving $T_{b}$.

It is based on pixel homogeneity $\Delta T_{11 \mathrm{~h}}$, which is the pixel homogeneity parameter of the $11.45-\mu \mathrm{m}$ brightness temperature $T_{11 \mathrm{~h}}$ at $375-\mathrm{m}$ resolution. The $\Delta T_{11 \mathrm{~h}}$ was defined as (Rosenfeld et al. 2014b)

$$
\Delta T_{11 \mathrm{~h}}=\frac{1}{4} \sum_{i=1}^{4}\left|T_{11 \mathrm{~h}_{i}}-\overline{T_{11 \mathrm{~h}}}\right|
$$

where $\overline{T_{11 \mathrm{~h}}}$ is the brightness temperature average of four pixels in the $375-\mathrm{m}$-resolution channel that reside 


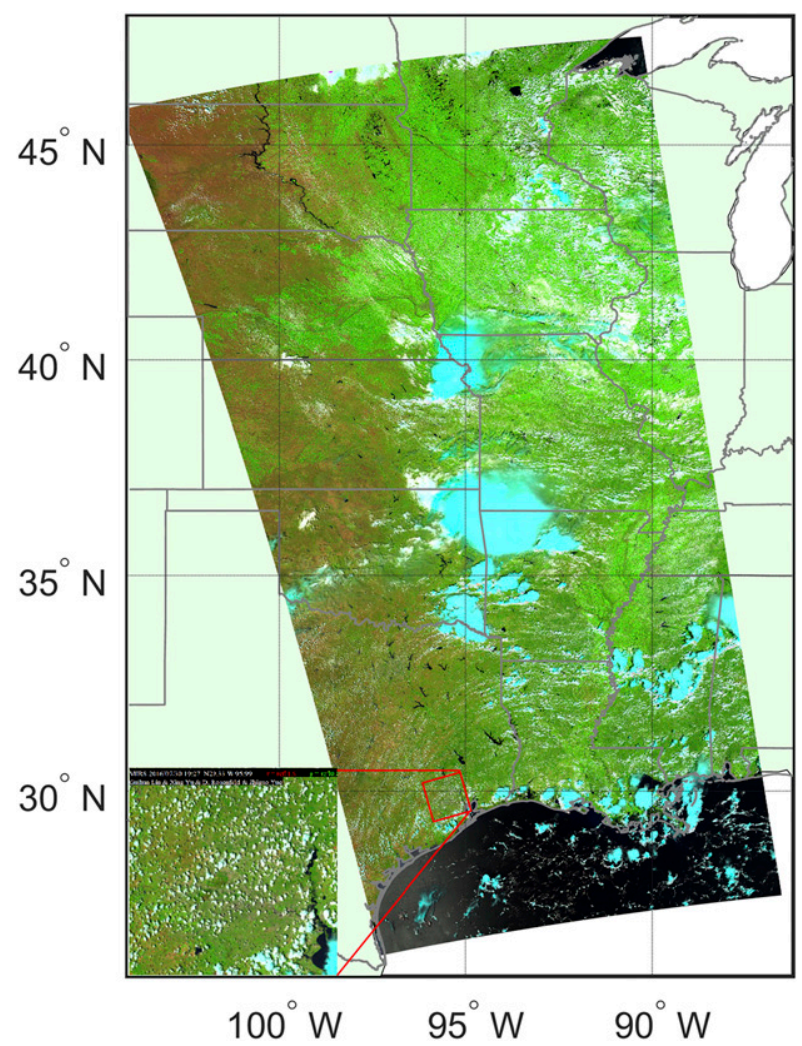

FIG. 5. Day-natural RGB composite image of 375-m resolution (red: $\rho_{1.6 \mathrm{~h}}$; green: $\rho_{0.8 \mathrm{~h}}$; blue: $\rho_{0.6 \mathrm{~h}}$ ), for which the satellite zenith angle is between $-20^{\circ}$ and $50^{\circ}$ and which was acquired around 1930 UTC 30 Jul 2016. In this color scheme, vegetation, water clouds with small droplets, snow and ice clouds, bare ground, and the ocean appear greenish, whitish, cyan, brown, and black, respectively (Lensky and Rosenfeld 2008).

within one $750-\mathrm{m}$-resolution pixel and $T_{11 \mathrm{~h}_{i}}$ is the $T_{11 \mathrm{~h}}$ of each these four points, respectively. If $\Delta T_{11 \mathrm{~h}}$ is greater than the given threshold $\left(\Delta T_{11 \mathrm{~h} \_ \text {threshold }}=1^{\circ} \mathrm{C}\right)$, it is considering to be a mixed pixel by cloud and surface. All of the pixels within the moving window are sorted by their $T_{11 \mathrm{~h}}$. The warmest $T_{11 \mathrm{~h}}$ for which a percentile $\Delta T_{11 \mathrm{~h}}\left(P_{-} \Delta T_{11 \mathrm{~h}}\right)$ of $\Delta T_{11 \mathrm{~h}}<\Delta T_{11 \mathrm{~h} \_ \text {threshold }}$ is considered to be the $T_{b}$. A value of $P \_\Delta T_{11 \mathrm{~h}}=30 \%$ was found to be optimal (Zhu et al. 2014). This method was validated against a combination of ceilometer and sounding with $T_{b}$ RMS error of $1.1^{\circ} \mathrm{C}$ over the SGP site. An error of $\pm 1.1^{\circ} \mathrm{C}$ in $T_{b}$ propagates to an $\sim 5 \%$ error in the retrieved $N_{d, a}$ (Rosenfeld et al. 2016).

\section{g. Identification the adiabatic $r_{e}$ and retrieval CCN}

Because the calculation of $\mathrm{CCN}$ is based on the adiabatic assumption of convective clouds, it is very important to identify the nearly adiabatic part from the $T-r_{e}$ profile of convective clouds. To avoid the inauthentic $r_{e}$ of nearby cloud base that is due to surface

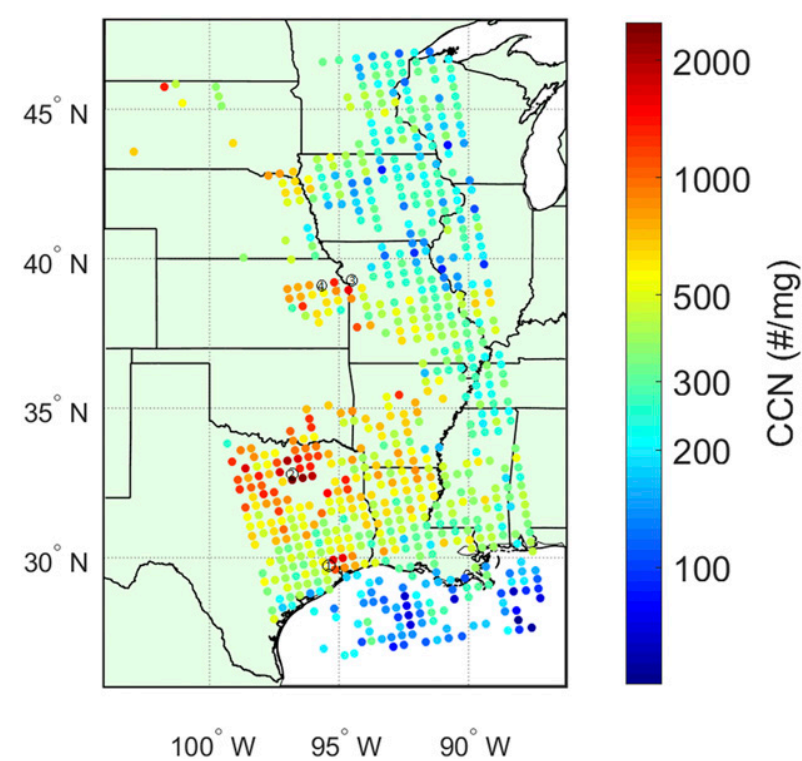

FIG. 6. Distribution of cloud-base $\mathrm{CCN}$ concentration $N_{\mathrm{CCN}}$ $\left(\mathrm{mg}^{-1}\right)$ retrieved from the VIIRS observations of Fig. 5. The color in the solid circles represents the $N_{\mathrm{CCN}}$, and the units are per unit mass of air, such that changes in air density do not change the $N_{\mathrm{CCN}}$ mixing ratio $\left(\mathrm{mg}^{-1}\right)$.

contamination, the warmest temperature level is skipped. If $r_{e}>15 \mu \mathrm{m}$ at their lowest $500 \mathrm{~m}$ or $r_{e}>20 \mu \mathrm{m}$ in the $T-r_{e}$ profile, an underestimate of $\mathrm{CCN}$ would otherwise result because of active cloud droplet coalescence or heavily precipitation. Therefore, the approximate adiabatic part of convective clouds will be searched from $T_{b}-1^{\circ} \mathrm{C}$ with $r_{e}<15 \mu \mathrm{m}$ at the lowest $500 \mathrm{~m}$ to the $T$ with the first $r_{e}=20 \mu \mathrm{m}\left(T_{20 \mu \mathrm{m}}\right) . \mathrm{LWC}_{a}$ should increase monotonically with decreasing temperature or increasing droplet mass in an ideal adiabatic condition. Therefore, the slope of linear best fit is calculated between $\mathrm{LWC}_{a}$ and $\mathrm{Mr}_{v, a}$ from $T_{b}-1^{\circ} \mathrm{C}$ to each $T$ with $T<T_{20 \mu \mathrm{m}}$, and the fit is forced to $\mathrm{Mr}_{v, a}=0$ at $\mathrm{LWC}_{a}=0$. The maximum slope is the end of adiabatic process and the respective $N_{d, a}$ [Eq. (2)]. Because of the mean deviation from the extreme inhomogeneous mixing assumption, the $N_{\mathrm{CCN}}$ is equal to $N_{d, a}$ divided by 1.3 (Freud et al. 2011; Rosenfeld et al. 2014a, 2016).

\section{h. Quality control and display}

A postprocessing procedure is to eliminate the convective clouds that are not suitable for retrieval boundary layer CCN. These cloud bases are elevated and, consequently, not coupled to the surface. The filtering of such elevated clouds is made mainly by analyzing the spatial distribution of $T_{b}$. Each $T_{b}$ is compared with all $T_{b}$ in the box area of $2^{\circ} \times 2^{\circ}$ latitude and longitude that is centered on itself. The median 


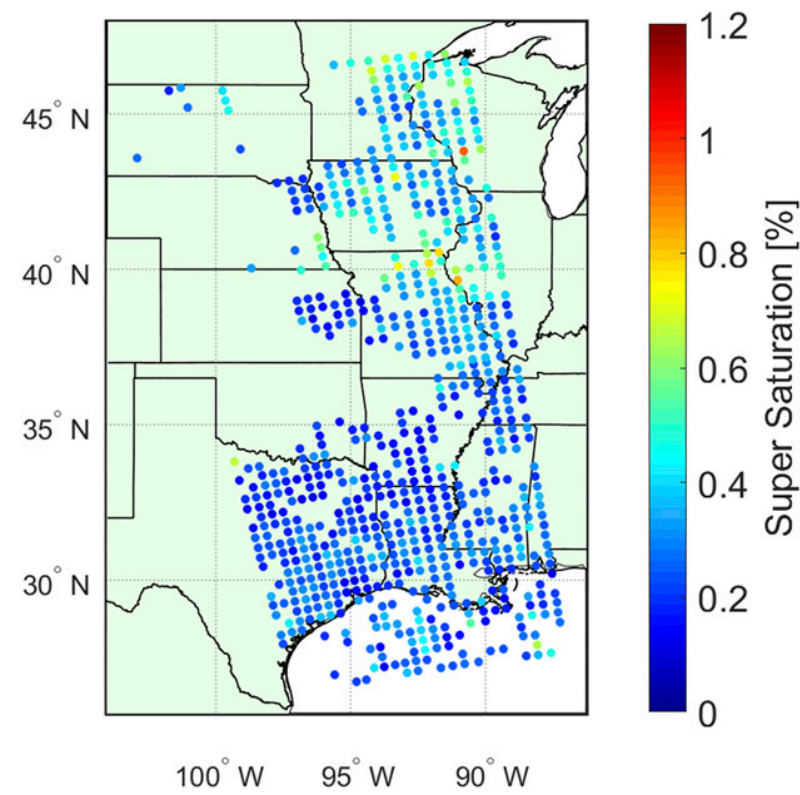

FIG. 7. As in Fig. 6, but for cloud-base supersaturation $S$ (\%; colors in circles) retrieved from VIIRS of Fig. 5.

of $T_{b}$, or $T_{b, m}$, the 75th-percentile terrain height $H_{75 \text { th }}$, and the standard deviation of terrain height $H_{\text {std }}$ are calculated in this area. If $H_{75 \text { th }}<H_{\text {std }}$, the moving window is identified as occurring over flat land. If $\left|T_{b}-T_{b, m}\right|>3^{\circ} \mathrm{C}$ over the ocean or flat land, the $T_{b}$ is considered to be an outlier and is filtered out. This procedure is not applied over rough terrain $\left(H_{75 \text { th }}>\right.$ $H_{\text {std }}$ ) that may cause large gradients in $T_{b}$. Isolated windows of marine clouds are defined as those that have less than 10 moving windows in the range of $1^{\circ}$ of latitude and longitude and are filtered if their $T_{b}$ is $5^{\circ} \mathrm{C}$ warmer or colder than the NCEP FNL data computed LCL temperature $T_{\mathrm{LCL}}$ for the examined window. By applying these criteria, a large portion of the elevated cloudy windows is filtered out. The criteria were tuned over homogeneous areas with no obvious reasons for changes in aerosols or meteorological conditions.

\section{Applications}

The output parameters include the latitude and longitude, $T_{b}, H_{b}, T_{14}, D_{14}, T_{g}, N_{\mathrm{CCN}}, S$, and other auxiliary analysis data such as temperature, pressure, relative humidity, and height profile from the FNL data (Table 1). Then, the map of the microphysical properties is displayed graphically.

The applied scene is one SNPP/VIIRS granule of satellite zenith angle between $-20^{\circ}$ and $50^{\circ}$ acquired around 1930 UTC 30 July 2016 , covering an area from $23^{\circ}$ to $47^{\circ} \mathrm{N}$ and from $118^{\circ}$ to $82^{\circ} \mathrm{W}$. The "day natural"

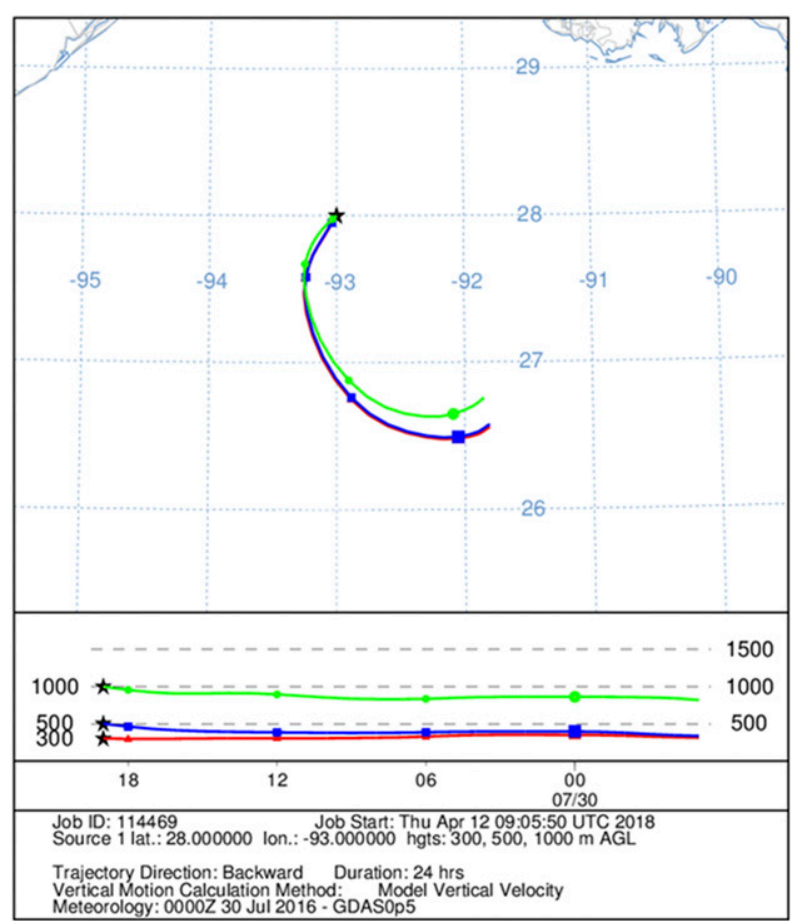

FIG. 8. NOAA HYSPLIT Model backward trajectories ending at different heights at a point $\left(28^{\circ} \mathrm{N}, 93^{\circ} \mathrm{W}\right)$ over the Gulf of Mexico at 1900 UTC 30 Jul 2016.

red-green-blue (RGB) composite image (Lensky and Rosenfeld 2008) of 375-m resolution showed some deep convective cloud clusters located both inland and along the southern coast (Fig. 5). Shallow convective clouds are found in most regions except for more arid parts of the north-central United States.

The distribution of cloud base $N_{\mathrm{CCN}}$ (Fig. 6) with their corresponding $S$ (Fig. 7) shows that the higher $N_{\mathrm{CCN}}$ occurred over the coastal plain, especially above big cities such as Houston and Dallas in Texas, Kansas City (Missouri), and Topeka, Kansas (numbers 1-4 of the black small circles in Fig. 6). Above these cities, $N_{\mathrm{CCN}}$ are very high (exceeding $1000 \mathrm{mg}^{-1}$ ) probably because of air pollution, and the corresponding $S$ is lower than $0.2 \%$. Areas inland far from pollution sources exhibit relatively low $N_{\mathrm{CCN}}$ of about 200 $300 \mathrm{mg}^{-1}$, and the corresponding $S$ is about $0.3 \%$. The clouds over the northern Gulf of Mexico are generally clean with $N_{\mathrm{CCN}}$ of approximately $100 \mathrm{mg}^{-1}$, and the corresponding $S$ is higher than $0.3 \%$ because the air was from the sea, which is relatively clean (Fig. 8).

The distribution of $T_{b}$ of the convective clouds in this granule is displayed in Fig. 9. A salient feature is their high $T_{b}$ (about $25^{\circ} \mathrm{C}$ ) over the Gulf of Mexico and the coastal plain. $T_{b}$ decreases as clouds are located at higher latitudes and farther inland. The $T_{b}$ of 

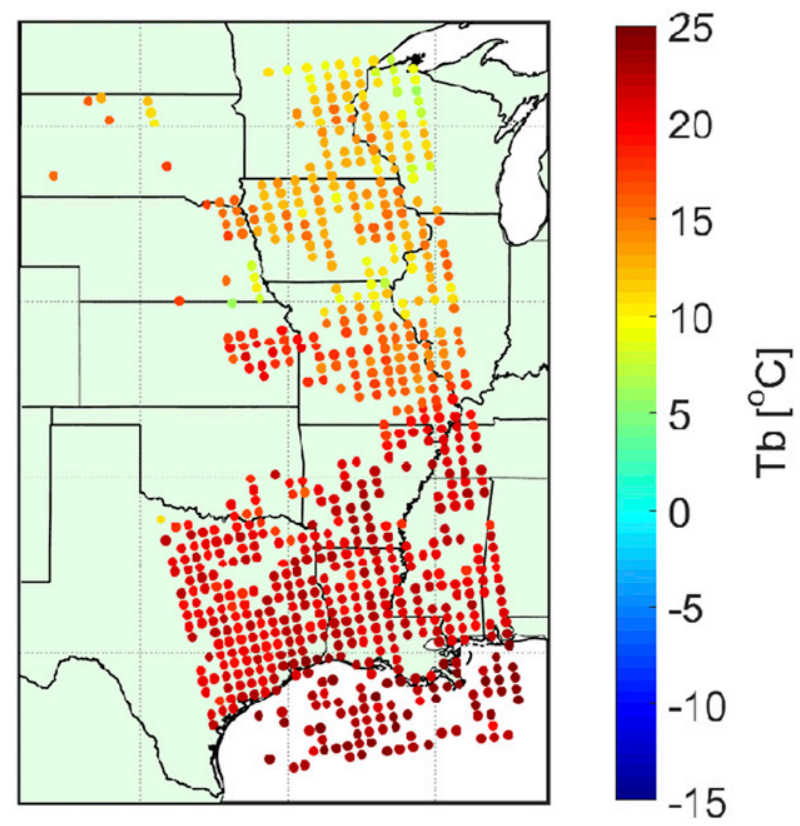

$100^{\circ} \mathrm{W} \quad 95^{\circ} \mathrm{W} \quad 90^{\circ} \mathrm{W}$

FIG. 9. As in Fig. 6, but for cloud-base temperature $T_{b}\left({ }^{\circ} \mathrm{C}\right.$; colors in circles).

convective clouds above Wisconsin and Minnesota is between $10^{\circ}$ and $15^{\circ} \mathrm{C}$, while very few of those above the Midwest are as low as $5^{\circ} \mathrm{C}$. The cloud-base updrafts $W_{b}$ are generally low over ocean $\left(0.5-0.8 \mathrm{~m} \mathrm{~s}^{-1}\right)$ and are nearly doubled over land (Fig. 10). The distribution of $W_{b}$ does not show excess over the polluted major urban areas with peak $N_{\mathrm{CCN}}$ in Fig. 6. This means that the maxima of $N_{\mathrm{CCN}}$ can be attributed primarily to the added aerosols and not to other possible dynamic factors, such as the urban heat island.

Most $D_{14}$ (Fig. 11) over the Gulf of Mexico are less than $500 \mathrm{~m}$, suggesting that the cloud forms precipitation there easily. It shows that most $D_{14}$ inland exceeds $500 \mathrm{~m}$, except for areas with low $N_{\mathrm{CCN}}$. Some $D_{14}$ in the high $N_{\mathrm{CCN}}$ inland area are greater than $2000 \mathrm{~m}$, indicating that the clouds in these areas are less prone to producing warm rain.

In addition, two retrieval $N_{\mathrm{CCN}}$ distributions are shown below. Many of the small convective clouds are located in Texas, Louisiana, Mississippi, Arkansas, and eastern Oklahoma in a day-natural RGB composite image of $375-\mathrm{m}$ resolution on 18 August 2017 acquired around 1926 UTC (Fig. 12). The distribution of cloud base $N_{\mathrm{CCN}}$ (Fig. 13) retrieved from VIIRS of Fig. 12 shows that the higher $N_{\mathrm{CCN}}$ occurred over the big cities such as Houston $\left(850-1050 \mathrm{mg}^{-1}\right)$, Dallas $\left(1300 \mathrm{mg}^{-1}\right)$, south of San Antonio, Texas (950$\left.1200 \mathrm{mg}^{-1}\right)$, and New Orleans, Louisiana $\left(1100 \mathrm{mg}^{-1}\right)$

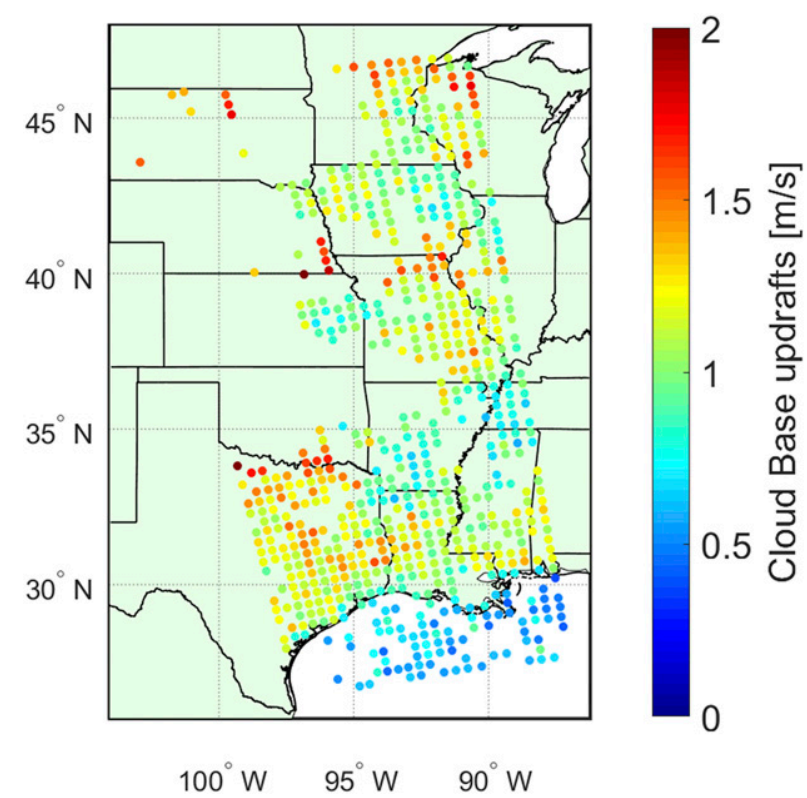

FIG. 10. As in Fig. 6, but for cloud-base updrafts $W_{b}\left(\mathrm{~m} \mathrm{~s}^{-1}\right.$; colors in circles).

(numbers 1-4 of the black small circles in Fig. 13). The $N_{\mathrm{CCN}}$ exceeds $1000 \mathrm{mg}^{-1}$ in many parts of Arkansas and eastern Oklahoma. Most of the areas in Fig. 14 are distributed with small convective clouds at 1930 UTC 4 August 2016. The $N_{\mathrm{CCN}}$ distribution (Fig. 15) that is retrieved from Fig. 14 reproduces the distribution of Figs. 6 and 13. The $N_{\mathrm{CCN}}$ over the Gulf of Mexico is generally $100-500 \mathrm{mg}^{-1}$. These regions inland far from

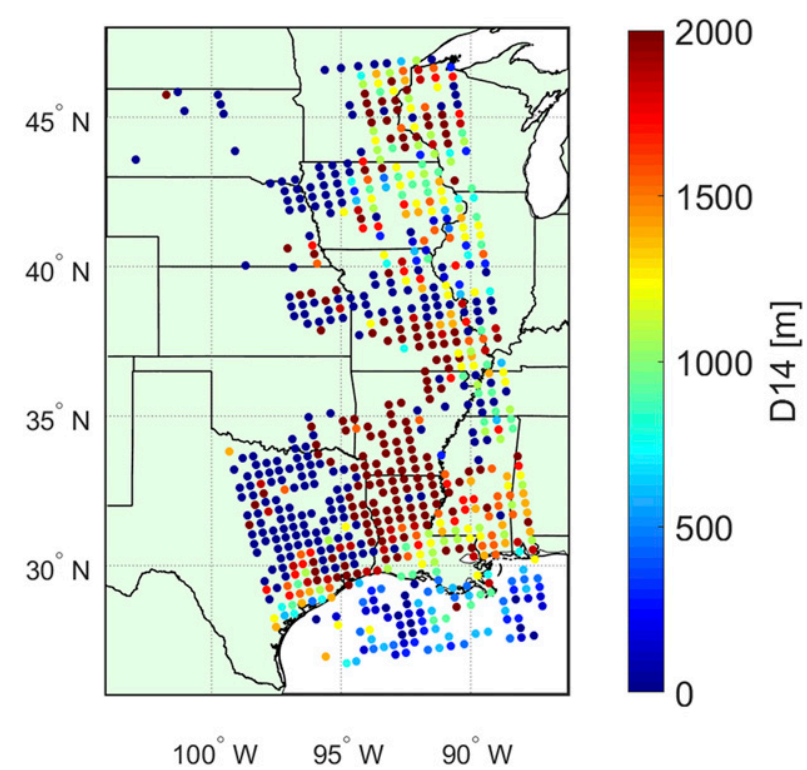

FIG. 11. As in Fig. 6, but for precipitation initialization depth $D_{14}$ ( $\mathrm{m}$; colors in circles). 


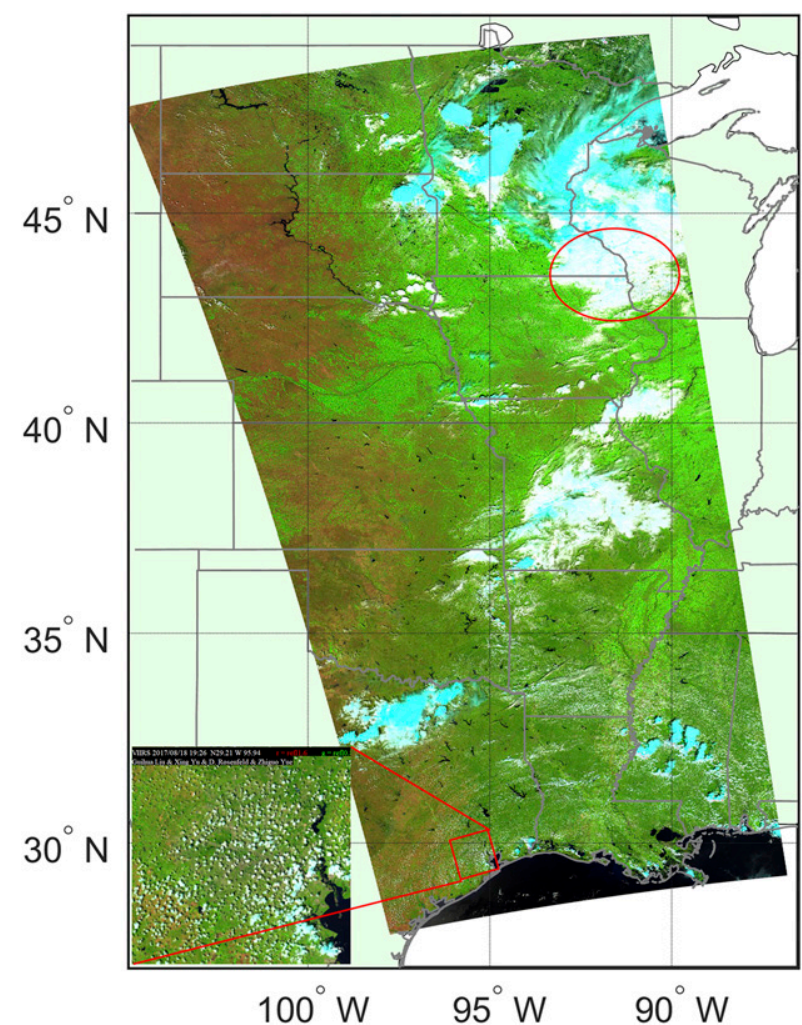

FIG. 12. As in Fig. 5, but acquired around 1926 UTC 18 Aug 2017. See the text for an explanation of the red circle.

the big cities expose relatively low $N_{\mathrm{CCN}}$. The edges of the large-scale stratocumulus clouds in the red circle in Fig. 12 are still incorrectly identified as convective clouds, and $N_{\mathrm{CCN}}$ is retrieved in the corresponding red circle in Fig. 13. This is also one of the places where our algorithm needs to be improved.

\section{Limitations of applicability}

This retrieval method has the following limitations that need to be improved:

1) At present, the retrieval algorithm is addressing only coupled small-scale convective clouds of only part of the swath width during the daytime. Retrieval for stratocumulus and layer clouds requires a different approach, which is presently being developed.

2) The CVI is based on the average correlation coefficient $\left(T-r_{e}\right)$ of each cloud pixel. To reduce statistical instability, we use a sliding area of $25 \times 25$ pixels for each pixel in moving window. Some layer clouds may still not always be completely excluded. Improving the algorithm is a subject of additional study.

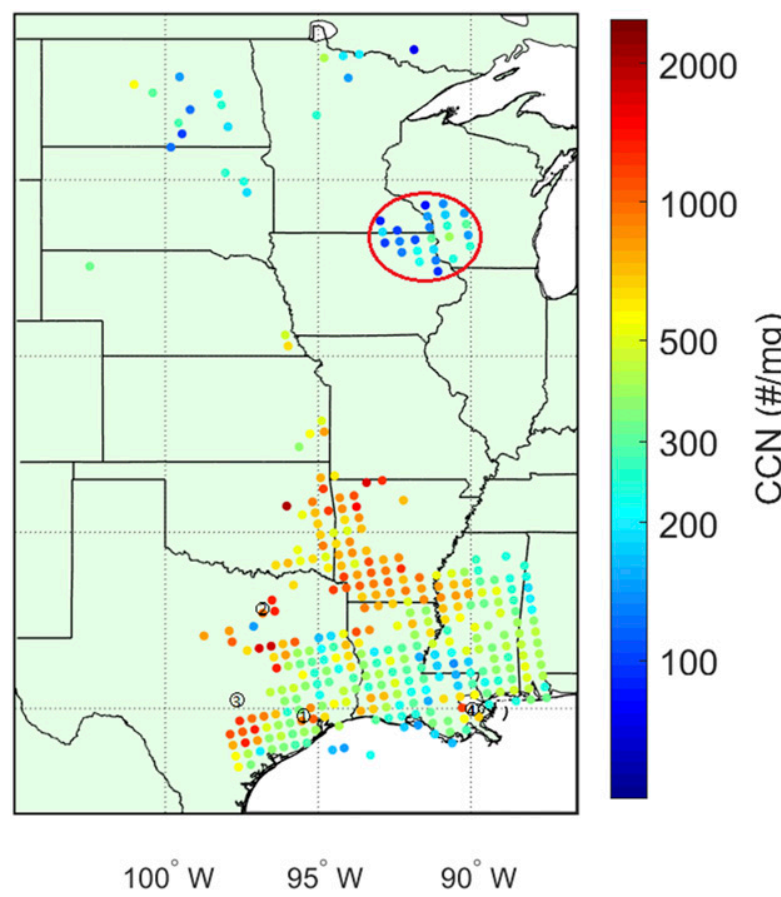

FIG. 13. As in Fig. 6, but retrieved from the VIIRS observations of Fig. 12. See the text for an explanation of the red circle.

3) When the moving window is fully cloudy, $T_{b}$ is obscured from the satellite view, and therefore $\mathrm{CCN}$ is not retrievable.

4) When the moving window is obscured by mid- and high-level clouds, the $T-r_{e}$ relationships cannot be retrieved.

5) The accuracy of the $N_{\mathrm{CCN}}, S, W_{b}$, and $D_{14}$ is very sensitive to the precision of the retrieved $T_{b}$. Therefore, more instruments' observation values of $N_{\mathrm{CCN}}$ and $T_{b}$ are needed to improve the retrieval methods and these values' accuracy.

6) The empirical formula of $W_{b}$ comes from the analysis of individual SGP site data. Because the $W_{b}$ has no clear reason to simply depend on cloudbase height alone, we also need to verify the accuracy and applicability of this relationship in other places where observation equipment is available.

7) There are numerous in situ studies that indicate broad variability in cloud vertical profiles deviating from adiabatic behavior for cumulus clouds (Brenguier et al. 2011; Min et al. 2012). The uncertainty inherent in this model for retrieval applications of cloud droplet number concentration also results in high retrieval uncertainty (Merk et al. 2016; Miller et al. 2016). Reducing the uncertainty of these variables is one of our priorities in the future. 


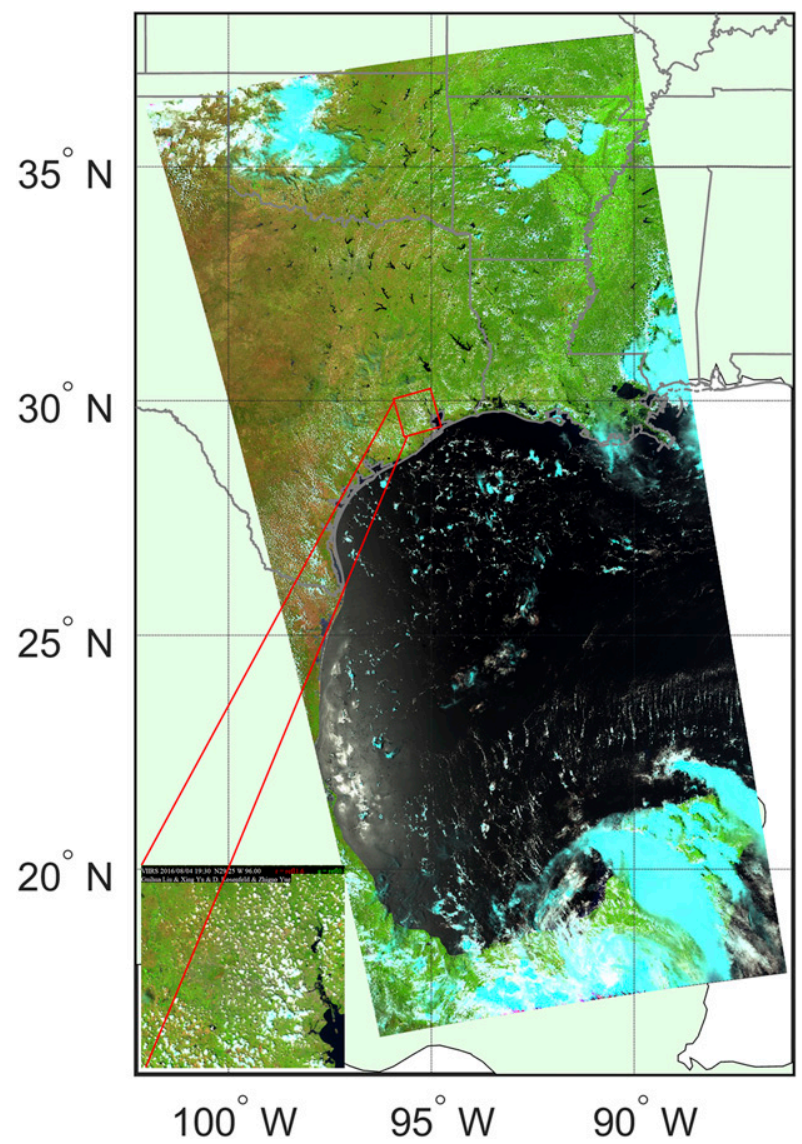

FIG. 14. As in Fig. 5, but acquired around 1930 UTC04 Aug 2016.

8) The retrieval algorithm is not suitable for surface areas covered with snow or ice because of the lack of thermal and visible contrast to the clouds.

\section{Summary}

The latest development of the Automated Mapping of Convective Clouds is presented in this study. The AMCC system inputs the VIIRS data and the NCEP FNL data and produces retrieved maps of $N_{\mathrm{CCN}}, S, T_{b}$, $W_{b}, H_{b}$, and $D_{14}$. It does so with a library of modules of data processing, image segmentation, moving-window setting, cloud pixel identification, convective cloud detection, microphysical property retrieval of convective clouds, and quality control.

These capabilities of AMCC have been demonstrated in this paper for three case studies over the central area of the United States and the Gulf of Mexico. The $N_{\mathrm{CCN}}$ distribution map over a large domain including the Gulf of Mexico, the coastal plain, and the central United States demonstrates its ability to capture the expected spatial distribution of the $N_{\mathrm{CCN}}$

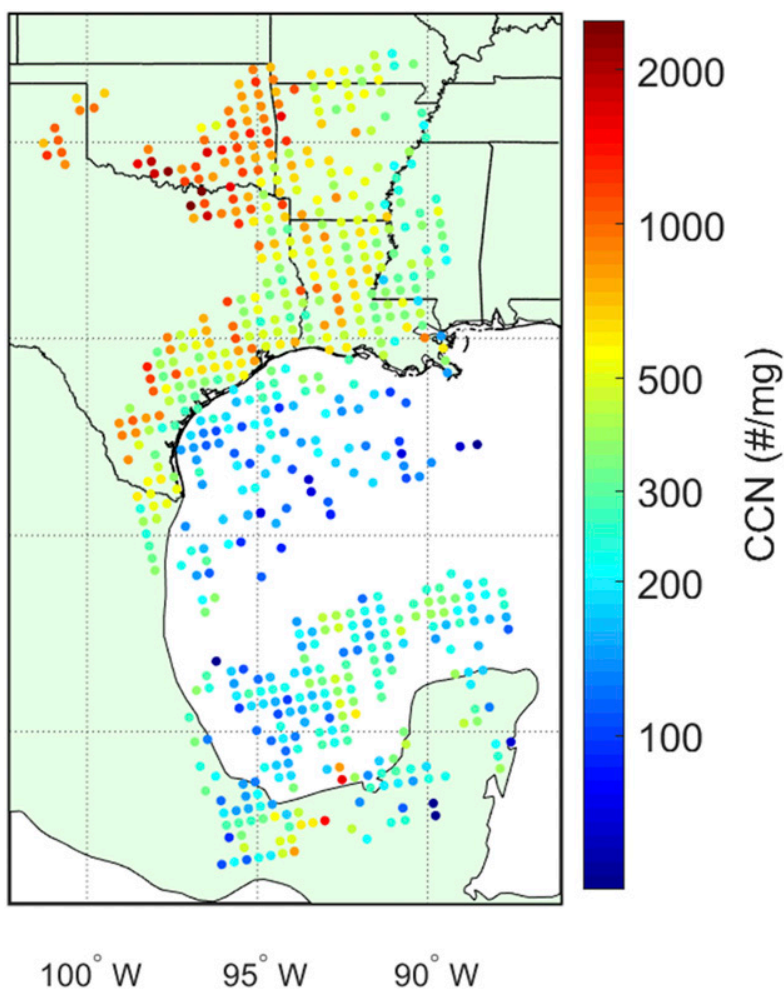

FIG. 15. As in Fig. 6, but retrieved from the VIIRS observations of Fig. 14.

values, from lower $N_{\mathrm{CCN}}$ values over ocean regions to gradual increasing concentrations with distance inland, and to very high concentrations surrounding big cities due to anthropogenic emissions. The obtained results demonstrate the feasibility of applying this method operationally. The global mapping of $N_{\mathrm{CCN}}$ at a spatial resolution of $36 \times 36 \mathrm{~km}^{2}$ is possible only with satellites. This can be used for the improvement of global and regional weather modeling. The maps as shown in Figs. 6, 11, 13, and 15 can be used by environmental agencies and for improving quantitative precipitation prediction.

Acknowledgments. We are very grateful to three anonymous reviewers for their insightful comments, questions, and suggestions, which have helped to greatly improve this paper. This work was supported by the Joint NSFC-ISF Research Program (41561144004), jointly funded by the National Natural Science Foundation of China and the Israel Science Foundation, the National Natural Science Foundation of China (41575136), and the National Key R\&D Program of China (2018YFC1507903). We also are grateful to NOAA for supplying VIIRS satellite and NCEP FNL data. 


\section{REFERENCES}

Andreae, M. O., 2009: Correlation between cloud condensation nuclei concentration and aerosol optical thickness in remote and polluted regions. Atmos. Chem. Phys., 9, 543-556, https:// doi.org/10.5194/acp-9-543-2009.

— , and D. Rosenfeld, 2008: Aerosol-cloud-precipitation interactions. Part 1. The nature and sources of cloud-active aerosols. Earth-Sci. Rev., 89, 13-41, https://doi.org/10.1016/ j.earscirev.2008.03.001.

,-- , P. Artaxo, A. A. Costa, G. P. Frank, K. M. Longo, and M. A. F. Silva-Dias, 2004: Smoking rain clouds over the Amazon. Science, 303, 1337-1342, https://doi.org/10.1126/ science.1092779.

Baum, B. A., and Q. Trepte, 1999: A grouped threshold approach for scene identification in AVHRR imagery. J. Atmos. Oceanic Technol., 16, 793-800, https://doi.org/10.1175/1520-0426(1999) 016<0793:AGTAFS $>2.0 . C O ; 2$.

Beals, M. J., J. P. Fugal, R. A. Shaw, J. Lu, S. M. Spuler, and J. L. Stith, 2015: Holographic measurements of inhomogeneous cloud mixing at the centimeter scale. Science, 350, 87-90, https://doi.org/10.1126/science.aab0751.

Braga, R. C., and Coauthors, 2017: Further evidence for CCN aerosol concentrations determining the height of warm rain and ice initiation in convective clouds over the Amazon basin. Atmos. Chem. Phys., 17, 14 433-14 456, https://doi.org/ 10.5194/acp-17-14433-2017.

Brenguier, J. L., F. Burnet, and O. Geoffroy, 2011: Cloud optical thickness and liquid water path-Does the $k$ coefficient vary with droplet concentration? Atmos. Chem. Phys., 11, 97719786, https://doi.org/10.5194/acp-11-9771-2011.

Burnet, F., and J.-L. Brenguier, 2007: Observational study of the entrainment-mixing process in warm convective clouds. J. Atmos. Sci., 64, 1995-2011, https://doi.org/10.1175/ JAS3928.1.

Coakley, J. A., M. A. Friedman, and W. R. Tahnk, 2005: Retrieval of cloud properties for partly cloudy imager pixels. J. Atmos. Oceanic Technol., 22, 3-17, https://doi.org/10.1175/JTECH1681.1.

Davis, A. B., and A. Marshak, 2010: Solar radiation transport in the cloudy atmosphere: A 3D perspective on observations and climate impacts. Rep. Prog. Phys., 73, 026801, https://doi.org/ 10.1088/0034-4885/73/2/026801.

Freud, E., and D. Rosenfeld, 2012: Linear relation between convective cloud drop number concentration and depth for rain initiation. J. Geophys. Res., 117, D02207, https://doi.org/ 10.1029/2011JD016457.

— J. Ström, D. Rosenfeld, P. Tunved, and E. Swietlicki, 2008: Anthropogenic aerosol effects on convective cloud microphysical properties in southern Sweden. Tellus, 60B, 286-297, https://doi.org/10.1111/j.1600-0889.2007.00337.x.

—, D. Rosenfeld, and J. R. Kulkarni, 2011: Resolving both entrainment-mixing and number of activated $\mathrm{CCN}$ in deep convective clouds. Atmos. Chem. Phys., 11, 12 887-12900, https://doi.org/10.5194/acp-11-12887-2011.

Godin, R., 2014: Joint polar satellite system (JPSS) VIIRS cloud mask (VCM) algorithm theoretical basis document (ATBD). JPSS Ground Project Code 474 Rep. 474-00033 (Revision E), 117 pp., https:/www.star.nesdis.noaa.gov/JPSS/documents/ATBD/ D0001-M01-S01-011_JPSS_ATBD_VIIRS-Cloud-Mask_E.pdf.

Hillger, D., and Coauthors, 2013: First-light imagery from Suomi NPP VIIRS. Bull. Amer. Meteor. Soc., 94, 1019-1029, https:// doi.org/10.1175/BAMS-D-12-00097.1.
Hutchison, K. D., B. D. Iisager, and R. L. Mahoney, 2013: Enhanced snow and ice identification with the VIIRS cloud mask algorithm. Remote Sens. Lett., 4, 929-936, https://doi.org/ 10.1080/2150704X.2013.815381.

Inoue, T., 1985: On the temperature and effective emissivity determination of semi-transparent cirrus clouds by bi-spectral measurements in the $10 \mu \mathrm{m}$ window region. J. Meteor. Soc. Japan Ser. II, 63, 88-99.

_- 1987: An instantaneous delineation of convective rainfall areas using split window data of NOAA-7 AVHRR. J. Meteor. Soc. Japan Ser. II, 65, 469-481, https://www.jstage.jst.go.jp/article/ jmsj1965/65/3/65_3_469/_pdf/-char/en.

Kaufman, Y. J., and T. Nakajima, 1993: Effect of amazon smoke on cloud microphysics and albedo-analysis from satellite imagery. J. Appl. Meteor., 32, 729-744, https://doi.org/10.1175/ 1520-0450(1993)032<0729:EOASOC >2.0.CO;2.

Konwar, M., R. S. Maheskumar, J. R. Kulkarni, E. Freud, B. N. Goswami, and D. Rosenfeld, 2012: Aerosol control on depth of warm rain in convective clouds. J. Geophys. Res., 117, D13204, https://doi.org/10.1029/2012JD017585.

Kopp, T. J., and Coauthors, 2014: The VIIRS Cloud Mask: Progress in the first year of $S-N P P$ toward a common cloud detection scheme. J. Geophys. Res. Atmos., 119, 2441-2456, https://doi.org/10.1002/2013JD020458.

Lensky, I. M., and D. Rosenfeld, 1997: Estimation of precipitation area and rain intensity based on the microphysical properties retrieved from NOAA AVHRR data. J. Appl. Meteor., 36, 234-242, https:// doi.org/10.1175/1520-0450(1997)036<0234:EOPAAR > 2.0.CO;2.

— , and — 2006: The time-space exchangeability of satellite retrieved relations between cloud top temperature and particle effective radius. Atmos. Chem. Phys., 6, 2887-2894, https:// doi.org/10.5194/acp-6-2887-2006.

, and —, 2008: Clouds-aerosols-precipitation satellite analysis tool (CAPSAT). Atmos. Chem. Phys., 8, 6739-6753, https://doi.org/10.5194/acp-8-6739-2008.

Marshak, A., and A. B. Davis, Eds., 2005: 3D Radiative Transfer in Cloudy Atmospheres. Springer, https://doi.org/10.1007/3-540-28519-9.

, S. Platnick, T. Várnai, G. Wen, and R. F. Cahalan, 2006: Impact of three-dimensional radiative effects on satellite retrievals of cloud droplet sizes. J. Geophys. Res. Atmos., 111, D09207, https://doi.org/10.1029/2005JD006686.

Merk, D., H. Deneke, B. Pospichal, and P. Seifert, 2016: Investigation of the adiabatic assumption for estimating cloud micro- and macrophysical properties from satellite and ground observations. Atmos. Chem. Phys., 16, 933-952, https://doi.org/ 10.5194/acp-16-933-2016.

Meyer, K., Y. Ping, and G. Bo-Cai, 2004: Optical thickness of tropical cirrus clouds derived from the MODIS 0.66 and $1.375 \mu \mathrm{m}$ channels. IEEE Trans. Geosci. Remote, 42, 833-841, https://doi.org/10.1109/TGRS.2003.818939.

Miller, D. J., Z. Zhang, A. S. Ackerman, S. Platnick, and B. A. Baum, 2016: The impact of cloud vertical profile on liquid water path retrieval based on the bispectral method: A theoretical study based on large-eddy simulations of shallow marine boundary layer clouds. J. Geophys. Res. Atmos., 121, 4122-4141, https:// doi.org/10.1002/2015JD024322.

Min, Q., and Coauthors, 2012: Comparison of MODIS cloud microphysical properties with in-situ measurements over the southeast Pacific. Atmos. Chem. Phys., 12, 11261-11273, https://doi.org/10.5194/acp-12-11261-2012.

Paluch, I. R., 1979: The entrainment mechanism in Colorado cumuli. J. Atmos. Sci., 36, 2467-2478, https://doi.org/10.1175/ 1520-0469(1979)036<2467:TEMICC > 2.0.CO;2. 
Pinsky, M., A. Khain, I. Mazin, and A. Korolev, 2012: Analytical estimation of droplet concentration at cloud base. J. Geophys. Res., 117, D18211, https://doi.org/10.1029/2012JD017753.

Prabha, T. V., A. Khain, R. S. Maheshkumar, G. Pandithurai, J. R. Kulkarni, M. Konwar, and B. N. Goswami, 2011: Microphysics of premonsoon and monsoon clouds as seen from in situ measurements during the Cloud Aerosol Interaction and Precipitation Enhancement Experiment (CAIPEEX). J. Atmos. Sci., 68, 1882-1901, https://doi.org/10.1175/2011JAS3707.1.

Quaas, J., B. Stevens, P. Stier, and U. Lohmann, 2010: Interpreting the cloud cover-aerosol optical depth relationship found in satellite data using a general circulation model. Atmos. Chem. Phys., 10, 6129-6135, https://doi.org/10.5194/acp-10-6129-2010.

Rosenfeld, D., 1999: TRMM observed first direct evidence of smoke from forest fires inhibiting rainfall. Geophys. Res. Lett., 26, 3105-3108, https://doi.org/10.1029/1999GL006066.

_ 2018: Cloud-aerosol-precipitation interactions based of satellite retrieved vertical profiles of cloud microstructure. Remote Sensing of Aerosols, Clouds, and Precipitation, Y. Hu, A. Kokhanovsky, and J. Wang, Eds., Elsevier, 129-152, https:// doi.org/10.1016/B978-0-12-810437-8.00006-2.

, and G. Gutman, 1994: Retrieving microphysical properties near the tops of potential rain clouds by multispectral analysis of AVHRR data. Atmos. Res., 34, 259-283, https://doi.org/ 10.1016/0169-8095(94)90096-5.

- and I. M. Lensky, 1998: Satellite-based insights into precipitation formation processes in continental and maritime convective clouds. Bull. Amer. Meteor. Soc., 79, 24572476, https://doi.org/10.1175/1520-0477(1998)079<2457: SBIIPF $>2.0 . \mathrm{CO} ; 2$.

— tained supercooled liquid water down to $-37.5^{\circ} \mathrm{C}$. Nature, $\mathbf{4 0 5}$, 440-442, https://doi.org/10.1038/35013030.

_ E. Cattani, S. Melani, and V. Levizzani, 2004: Considerations on daylight operation of 1.6- versus 3.7- $\mu \mathrm{m}$ channel on NOAA and METOP satellites. Bull. Amer. Meteor. Soc., 85, 873-882, https://doi.org/10.1175/BAMS-85-6-873.

— W. W. Woodley, T. W. Krauss, and V. Makitov, 2006: Aircraft microphysical documentation from cloud base to anvils of hailstorm feeder clouds in Argentina. J. Appl. Meteor. Climatol., 45, 1261-1281, https://doi.org/10.1175/JAM2403.1.

- — _ A. Lerner, G. Kelman, and D. T. Lindsey, 2008a: Satellite detection of severe convective storms by their retrieved vertical profiles of cloud particle effective radius and thermodynamic phase. J. Geophys. Res., 113, D04208, https://doi.org/10.1029/2007JD008600.

,,-- D. Axisa, E. Freud, J. G. Hudson, and A. Givati, 2008b: Aircraft measurements of the impacts of pollution aerosols on clouds and precipitation over the Sierra Nevada. J. Geophys. Res., 113, D15203, https://doi.org/10.1029/2007JD009544.

, and Coauthors, 2011: Glaciation temperatures of convective clouds ingesting desert dust, air pollution and smoke from forest fires. Geophys. Res. Lett., 38, L21804, https://doi.org/ 10.1029/2011GL049423.
— B. Fischman, Y. Zheng, T. Goren, and D. Giguzin, 2014a: Combined satellite and radar retrievals of drop concentration and CCN at convective cloud base. Geophys. Res. Lett., 41, 3259-3265, https://doi.org/10.1002/2014GL059453.

—, G. Liu, X. Yu, Y. Zhu, J. Dai, X. Xu, and Z. Yue, 2014b: High resolution $(375 \mathrm{~m})$ cloud microstructure as seen from the NPP/VIIRS satellite imager. Atmos. Chem. Phys., 14, 24792496, https://doi.org/10.5194/acp-14-2479-2014.

— , and Coauthors, 2016: Satellite retrieval of cloud condensation nuclei concentrations by using clouds as $\mathrm{CCN}$ chambers. Proc. Natl. Acad. Sci. USA, 113, 5828-5834, https://doi.org/ 10.1073/pnas.1514044113.

Roskovensky, J. K., and K. N. Liou, 2003: Detection of thin cirrus from $1.38 \mu \mathrm{m} / 0.65 \mu \mathrm{m}$ reflectance ratio combined with 8.6 $11 \mu \mathrm{m}$ brightness temperature difference. Geophys. Res. Lett., 30, 1985, https://doi.org/10.1029/2003GL018135.

Stevens, B., and G. Feingold, 2009: Untangling aerosol effects on clouds and precipitation in a buffered system. Nature, 461, 607-613, https://doi.org/10.1038/nature08281.

Stier, P., 2016: Limitations of passive remote sensing to constrain global cloud condensation nuclei. Atmos. Chem. Phys., 16, 6595-6607, https://doi.org/10.5194/acp-16-6595-2016.

Várnai, T., and A. Marshak, 2009: MODIS observations of enhanced clear sky reflectance near clouds. Geophys. Res. Lett., 36, L06807, https://doi.org/10.1029/2008GL037089.

Yuan, T., J. V. Martins, Z. Li, and L. A. Remer, 2010: Estimating glaciation temperature of deep convective clouds with remote sensing data. Geophys. Res. Lett., 37, L08808, https://doi.org/ 10.1029/2010GL042753.

Zhang, Z., A. S. Ackerman, G. Feingold, S. Platnick, R. Pincus, and H. Xue, 2012: Effects of cloud horizontal inhomogeneity and drizzle on remote sensing of cloud droplet effective radius: Case studies based on large-eddy simulations. J. Geophys. Res., 117, D19208, https://doi.org/10.1029/2012JD017655.

Zheng, Y., and D. Rosenfeld, 2015: Linear relation between convective cloud base height and updrafts and application to satellite retrievals. Geophys. Res. Lett., 42, 6485-6491, https:// doi.org/10.1002/2015GL064809.

$-\ldots$, and Z. Li, 2015: Satellite inference of thermals and cloud-base updraft speeds based on retrieved surface and cloud-base temperatures. J. Atmos. Sci., 72, 2411-2428, https:// doi.org/10.1175/JAS-D-14-0283.1.

,$- \ldots$, and — 2016: Quantifying cloud base updraft speeds of marine stratocumulus from cloud top radiative cooling. Geophys. Res. Lett., 43, 11 407-11 413, https://doi.org/10.1002/ 2016 GL071185.

Zhu, Y., D. Rosenfeld, X. Yu, G. Liu, J. Dai, and X. Xu, 2014: Satellite retrieval of convective cloud base temperature based on the NPP/VIIRS Imager. Geophys. Res. Lett., 41, 13081313, https://doi.org/10.1002/2013GL058970.

$,-\longrightarrow,-$, and Z. Li, 2015: Separating aerosol microphysical effects and satellite measurement artifacts of the relationships between warm rain onset height and aerosol optical depth. J. Geophys. Res., 120, 7726-7736, https://doi.org/10.1002/ 2015 JD023547. 